Kaur Alttoa

\title{
DIE KIRCHE ZU URBS/URVASTE UND DIE FRAGE DER RIGENSER BAUSCHULE IM 13. JAHRHUNDERT
}

In der Fachliteratur, welche die estnische mittelalterliche Sakral-architektur behandelt, sticht eine gewisse Disproportionalität ins Auge. ${ }^{1}$ Hauptsächlich hat man sich mit Kalksteinbauten in Nord- und Westestland beschäftigt. Südestland, wo Feld- und Backsteine als Baumaterial eingesetzt wurden, ist deutlich seltener in den Blickwinkel der Architekturhistoriker gelangt. Natürlich hat das zum einen etwas mit den Vorlieben der Forscher zu tun, aber vor allem ist der schlechte Erhaltungszustand der älteren Bausubstanz ausschlaggebend gewesen. Backsteine sind unter den hiesigen Klimabedingungen weniger dauerhaft als Kalkstein. Eine bedeutende Spur haben hier auch die Kriege hinterlassen. Insbesondere die Kämpfe der Schweden und der Polen in den Anfangsjahrzehnten des 17. Jahrhunderts, als die Mehrzahl der Kirchen zu Ruinen wurde. Aber so manches Mal können wirtschaftlich günstige Zeiten das Architekturerbe mehr zerstören, als Kriege. In der zweiten Hälfte des 19. Jahrhunderts tendierten viele der ländlichen Kirchen dazu, für die Gemeinde zu eng zu werden. Vor allem im finanziell wohlhabenderen Südestland fing man an, die Kirchen zu erweitern und umzubauen - all das fand auf

DOI: http://dx.doi.org/10.12697/BJAH.2013.6.01

Übersetzung aus dem Estnischen von Marju und Olaf Mertelsmann

1 Kaur Alttoa, „Eesti tellisgootika uurimisseisust”, Annales Societatis Litterarum Estonicae in Svecia XI. 1988-1990 (Stockholm, 1992), 9-10 


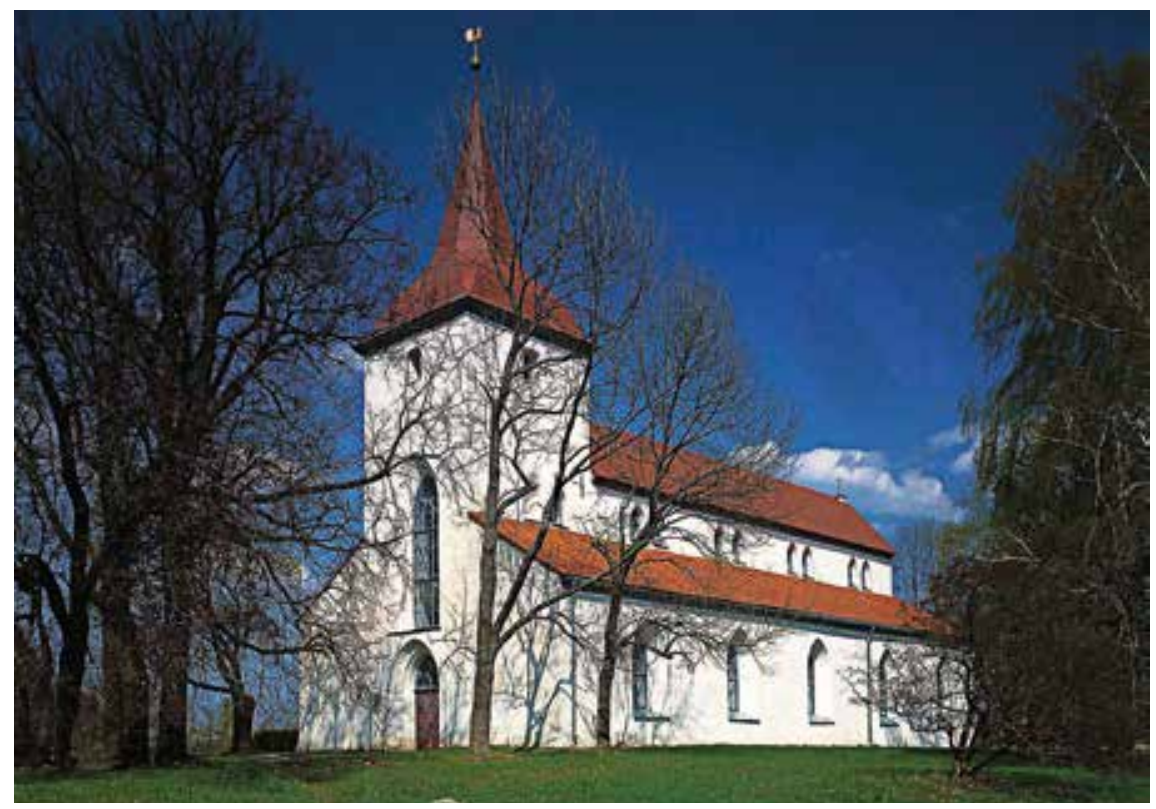

Abb. 1. Die Kirche zu Urbs aus Südwesten. Foto von Peeter Säre

Kosten der mittelalterlichen Bausubstanz statt. ${ }^{2}$ Als Ergebnis all dieser Entwicklungen ist ein Großteil der noch erhaltenen mittelalterlichen Bausubstanz heutzutage entweder mit einer Kulturschicht oder mit neuzeitlichem Putz bedeckt. Somit setzt eine erfolgreiche Untersuchung der älteren Architektur Südestlands im Allgemeinen zuerst umfangreiche Feldforschungen voraus. Dafür haben sich bis jetzt ziemlich wenige Gelegenheiten ergeben, weshalb der Forscher sich oftmals auf der Ebene der Vermutungen und der Hypothesen fortbewegen muss. Das Gesagte gilt auch für die Kirche zu Urbs, die im vorliegenden Artikel betrachtet wird. In so manchen Fällen können wir nur Fragen stellen. Die Antworten werden sich durch zukünftige systematische Untersuchungen ergeben.

2 Eines der markantesten Beispiele stellt die Kirche zu Hallist (estnisch: Halliste) im Landkreis Fellin (estnisch: Viljandimaa) dar. Die im Spätmittelalter gebaute Kirche ist im Laufe der Neuzeit mehrfach erweitert worden. Als Folge dessen sind von der ursprünglichen Kirche einzig und allein die ungefähr sieben Meter langen Mauerabschnitte der Längswände erhalten geblieben, die in den jetzigen Baukörper integriert worden sind. Siehe Kaur Alttoa, „Halliste keskaegsest kirikuhoonest”, Kunstiteadus. Kunstikriitika, 5 (Tallinn: Kunst, 1983), 142-144. 


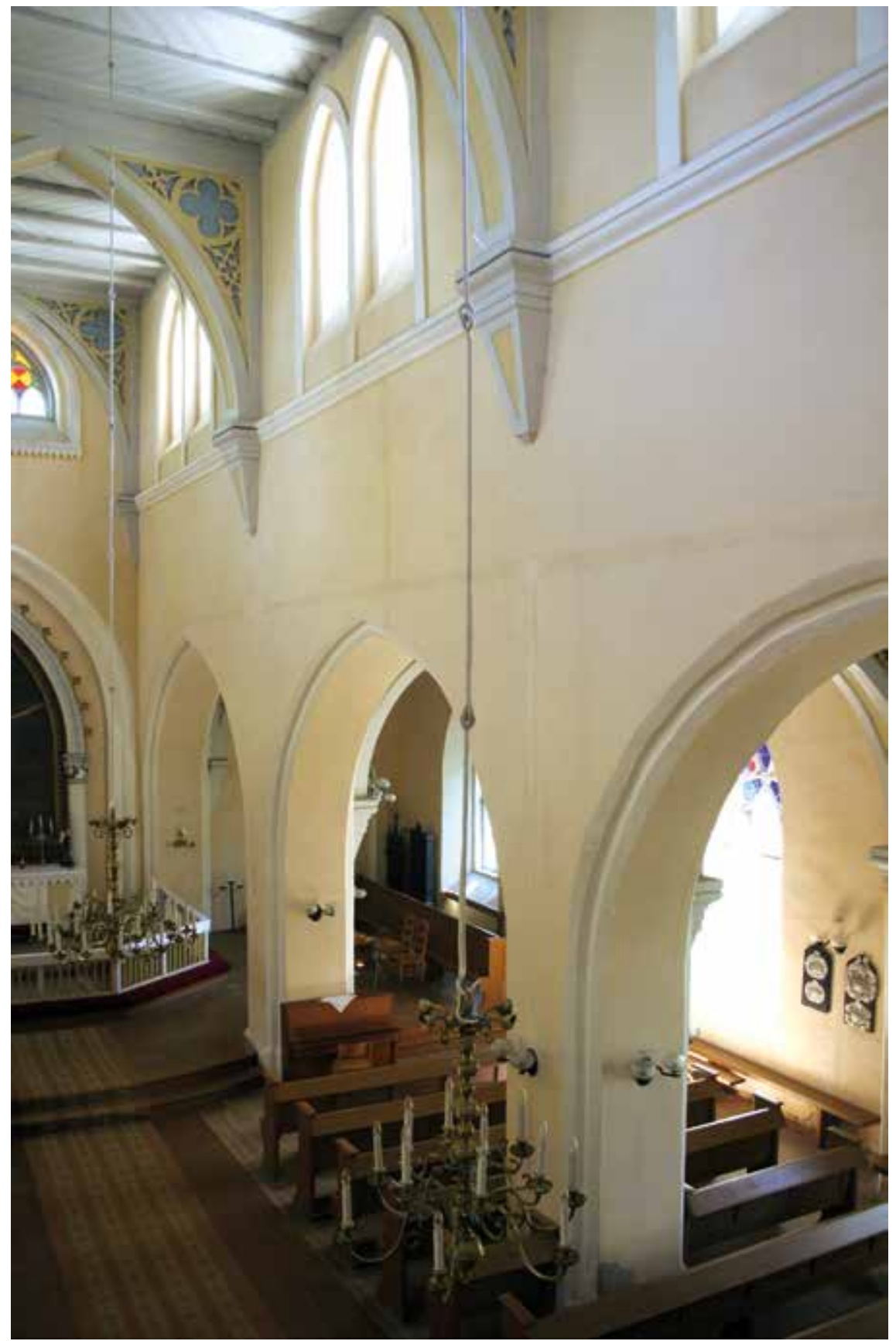

Abb. 2. Innenansicht. Foto von Kaur Alttoa, 2012 


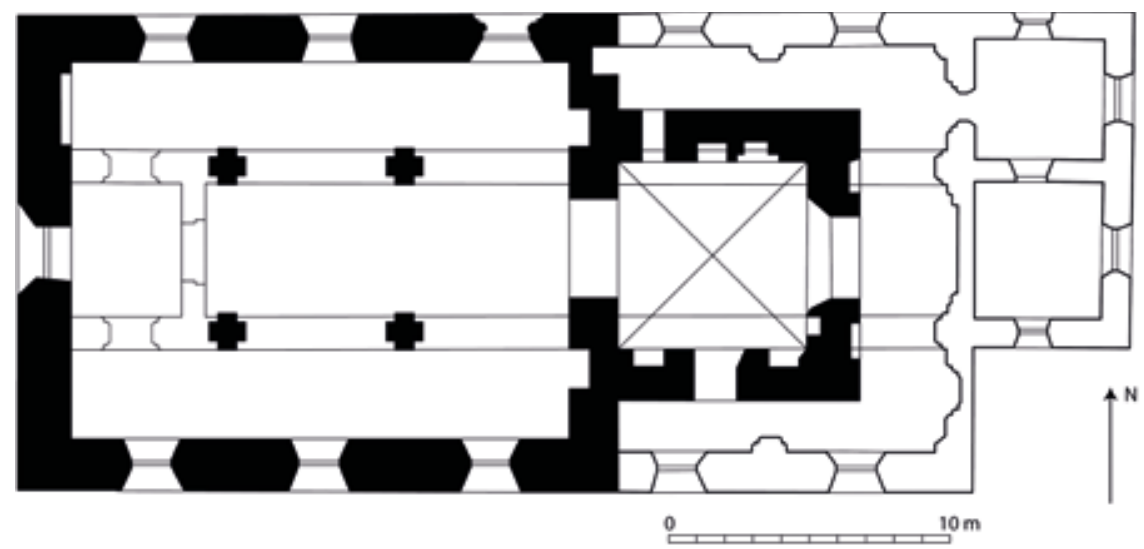

Abb. 3. Die mittelalterliche Kirche zu Urbs und die neuzeitlichen Erweiterungen. Zusammengestellt von Kaur Alttoa, gezeichnet von Kristel Külljastinen.

\section{DIE BASILIKA IN URBS}

Die Kirche zu Urbs (estnisch: Urvaste) im ehemaligen Bistum Dorpat (estnisch: Tartu) stellt eine große Ausnahme unter dem gesamten baulichen Erbe des mittelalterlichen Estlands dar: es handelt sich um die einzige basilikale Landkirche. Dessen ungeachtet hat die Kirche kaum die Aufmerksamkeit der Architekturhistoriker erlangt und bisher liegen keine gesonderten Behandlungen der Baugeschichte der Kirche vor. Vor allem hat man die Kirche als ein Glied in einer Reihe von Basiliken betrachtet, die mit den Rigenser Bautraditionen des 13. Jahrhunderts verbunden waren [die Jakobskirche in Riga, die Nikolaikirche in Pernau (estnisch: Pärnu), die Bartholomäuskirche in Rujen (lettisch: Rūjiena) und die Kirche zu Urbs].

Die mittelalterlichen Angaben über Urbs sind minimal. Offenbar gehörte das spätere Kirchspiel Urbs nicht zu den vorhistorischen Gauen, sondern ist erst im Mittelalter entstanden. ${ }^{3}$ Die Kirche wurde zum ersten Mal im Jahre 1413 erwähnt, als Papst Johannes XXIII. den Besuchern der parrochialis eccl. in Ansen den Ablass gewährte. ${ }^{4}$ Es handelt sich zweifelsohne um Urbs (in der älteren deutschsprachigen Überlieferung Anzen), das hiermit im Spätmittelalter zu den offiziellen Zielorten

3 Enn Tarvel, „Sakala ja Ugandi kihelkonnad”, Keel ja Kirjandus, 10 (1968), 590.

4 Leonid Arbusow, Livlands Geistlichkeit vom Ende des 12. bis ins 16. Jahrhundert. Separatdruck aus dem Jahrbuch für Genealogie, Heraldik und Sphragistik (Mitau: Steffenhagen, 1913), 312. 


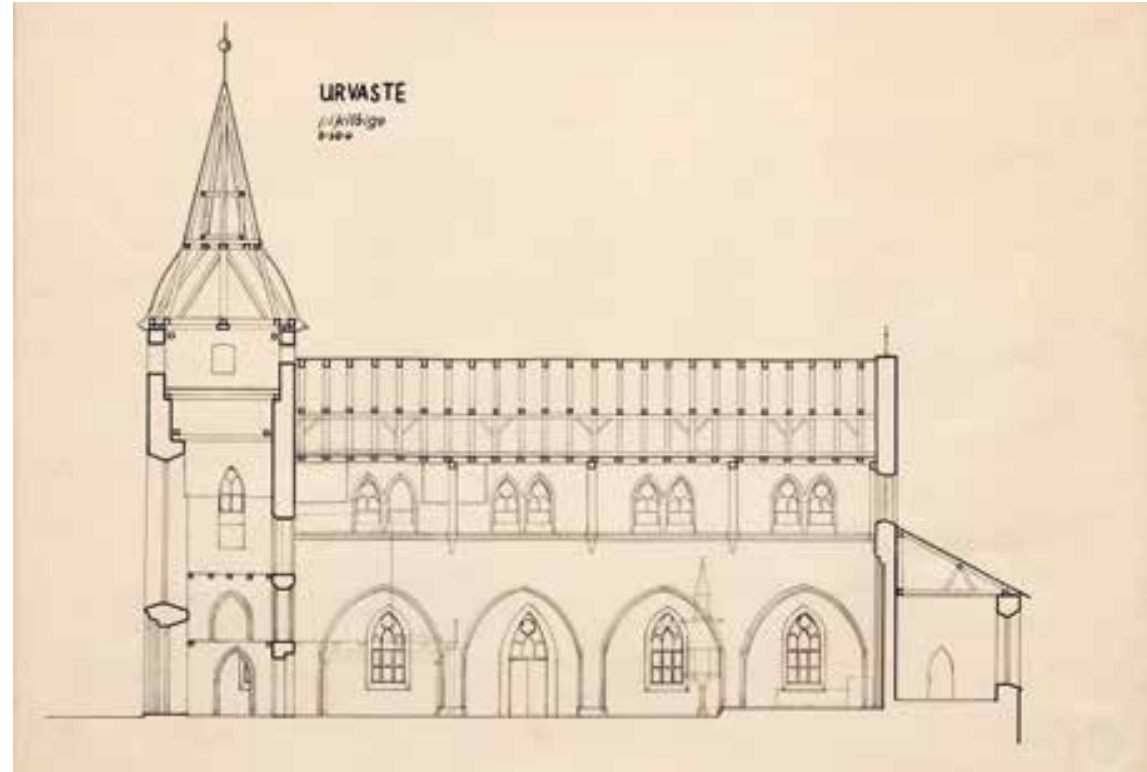

Abb. 4. Der Längsschnitt der Kirche zu Urbs. Gezeichnet von Edgar Saadre, 1942

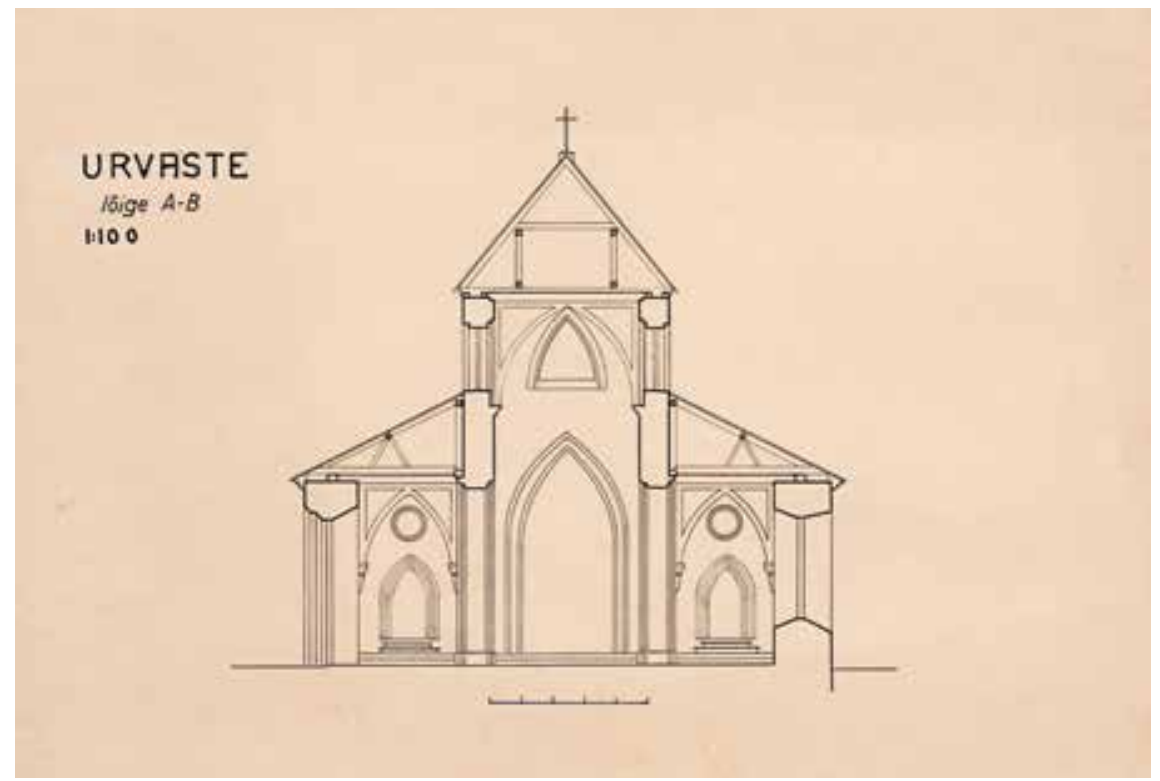

Abb. 5. Der Querschnitt der Kirche zu Urbs. Gezeichnet von Edgar Saadre, 1942 
von Wallfahrten gehörte. Der Namensheilige der Kirche ist allerdings unbekannt. ${ }^{5}$

So wie die Mehrzahl der mittelalterlichen Kirchen Südestlands, hat auch die Kirche zu Urbs mehrere Zerstörungen und Umbauten durchgemacht. Ihre jetzige Gestalt erhielt sie im Jahre 1889, als die östliche Wand des mittelalterlichen Langhauses und der Altarraum abgerissen wurden und das Gebäude um zwei Joche verlängert wurde. ${ }^{5}$ Die Situation vor dem Umbau widerspiegelt sich auf dem im Jahre 1896 von Reinhold Guleke veröffentlichten Plan und Querschnitt der Kirche. ${ }^{6}$ Das ursprünglich ohne einen Turm gewesene Langhaus war kurz und verfügte über einen Grundriss, der sich einem Quadrat annäherte. Zwei Paar Pfeiler teilten den Raum in drei Schiffe und in drei Joche auf. Die stämmigen Pfeiler haben einen kreuzförmigen Querschnitt mit abgekanteten Ecken. Eine Kapitell- oder Kämpferzone fehlt und die Pfeiler gehen fließend in niedrige Arkadenbögen über. Die Fenster des Lichtgadens sind auf außergewöhnliche Weise paarweise platziert. Die Hochwände wurden von dreieckigen Strebemauern an den Seitenschiffen gestützt. Der Chorraum mit einem quadratförmigen Grundriss war nur ein wenig breiter, als das Mittelschiff. In der östlichen Wand des Langhauses an zwei Seiten des verhältnismäßig schmalen Triumphbogens hat es geräumige Nischen gegeben - zweifelsohne weisen sie auf Nebenaltäre hin. Über die Gewölbe liegen keine näheren Angaben vor - sie waren bereits bis zum Anfang des 17. Jahrhunderts verfallen. Das Baumaterial ist nur im Falle der Hochwände bekannt. Sie sind aus Backsteinen imLäufer-Binder-Verband gebaut. ${ }^{7}$ Außergewöhnlicherweise hatte man in Urbs auch einen Westbau in der Breite des Langhauses angefangen - es ist sogar nicht ausgeschlossen, dass die Errichtung von zwei Türmen geplant gewesen war. Offenbar gehörte dieser westliche Bau nicht zu der ursprünglichen Anlage, sondern es handelte sich um eine spätere

5 Architekt Reinhold Guleke, Baumeister Jüri Teas. Eesti Ajalooarhiiv (Estnisches Historisches Archiv, weiterhin abgekürzt mit EAA), 1270-1-608, 2.

6 Reinhold Guleke, Alt-Livland. Mittelalterliche Baudenkmäler Liv-, Est-, Kurlands und Oesels (Leipzig: K. F. Koehler, 1896), F. III T. V; T. XXIII.5, a.

7 Für einen solchen Mauerverband hat man verschieden und teilweise widerspruchsvolle Bezeichnungen eingesetzt: polnischer, gotischer oder wendischer Verband. Die letztere wird auch von Gottfried Kiesow verwendet, Wege zur Backsteingotik. Eine Einführung (Bonn: Monumente Publikationen, 2007), 102. Die Tendenz, aus einer Beschreibung einen Terminus zu bilden, nimmt jedoch zu: Läufer-Binder-Verband (Barbara Perlich, Mittelalterlicher Backsteinbau. Zur Frage nach der Herkunft der Backsteintechnik, Berliner Beiträge zur Bauforschung und Denkmalpflege, 5 (Petersberg: Michael Imhof Verlag, 2007), 91). 
(womöglich spätmittelalterliche) Ergänzung. Diese Idee wurde aber bereits am Anfang der Bauarbeiten aufgegeben. ${ }^{8}$

\section{FORSCHUNGSGESCHICHTE}

Die erste architekturgeschichtliche Abhandlung über die Kirche zu Urbs hat Alfred Vaga vorgelegt, der sie im Vergleich mit der Nikolaikirche in Pernau (estnisch: Pärnu) betrachtete. Nach Auffassung dieses Autors ist die Kirche bereits bei ihrer Gründung als eine Basilika angelegt worden. Das hat in der Stilperiode der Spätgotik stattgefunden - erst am Ende des 15. Jahrhunderts oder am Anfang des 16. Jahrhunderts. Was die Vorbilder anbelangt, dann "gehören die Nikolaikirche in Pernau und die Kirche zu Urbs der Kirchengruppe des südlichen Gebiets von Alt-Livland an, dem heutigen Lettland, die auf Basis einer dominierenden Beeinflussung aus Nordwestdeutschland entstand. Dabei betont die Nikolaikirche in Pernau ihre unmittelbare Abhängigkeit von der Jakobskirche in Riga sowohl während der Periode der Hallenkirche als auch während derjenigen der Basilika, da Urbs hingegen durch enge Verwandtschaftszüge mit der Kirche in Rujen verbunden ist - mit einem Gebäude, dessen Vorbild scheinbar ebenso die Jakobskirche in Riga war. ${ }^{\prime 9}$ Armin Tuulse hat, während er die der Familie von Uexküll gehörende Vasallenburg von Antzen (estnisch: Antsla) behandelte, behauptet, dass der Umbau der Kirche zu Urbs zu einer Basilika Ende des 15. Jahrhunderts stattgefunden habe, möglicherweise sei damit Peter von Uexküll, der im Jahre 1484 verstarb, verbunden gewesen. ${ }^{10}$

Im Unterschied zu Armin Tuulse haben alle Forscher der Nachkriegszeit vermutet, dass die Kirche als Ganzes im Laufe einer einzigen Bauperiode entstanden sei. Voldemar Vaga verband die Kirche zu Urbs mit der Rigenser Schule, indem er auf die basilikale Raumform und auf die Pfeiler mit einem kreuzförmigen Plan hinwies, und datierte sie auf das 13. Jahrhundert. ${ }^{11}$ Auch Villem Raam hat auf das Vorbild der Basiliken

8 Im Jahre 1987 fanden dort Feldforschungen kleineren Umfangs statt, deren Zeichnungen und Notizen im damaligen Institut „Estnische Baudenkmäler” (estnisch: Eesti Ehitusmälestised) verblieben. Später ist es nicht gelungen, diese Materialien ausfindig zu machen.

9 Alfred Waga, Eesti kunsti ajalugu I (Tartu: Eesti Kirjanduse Selts, 1932), 116-118.

10 Armin Tuulse, „Die Burgen in Estland und Lettland”, Verhandlungen der Gelehrten Estnischen Gesellschaft, XXXIII (Dorpat: Dorpater Estnischer Verlag, 1942), 266.

11 Voldemar Vaga, Das Problem der Raumform in der mittelalterlichen Baukunst Lettlands und Estlands (Tartu: Staatliche Universität Tartu, 1960), 25-26. 
in Lettland hingewiesen und angenommen, dass die Kirche Ende des 13. oder Anfang des 14. Jahrhunderts gebaut wurde. ${ }^{12}$ Der Autor des vorliegenden Artikels hat als Bauzeit der Kirche den Anfang des 14. Jahrhunderts vorgeschlagen, ${ }^{13}$ wobei den einzigen Ausgangspunkt ein kleines Detail des Hauptportals darstellte.

\section{PROBLEME DER DATIERUNG DER KIRCHE}

Für eine Aufklärung der Baugeschichte der Kirche zu Urbs liegen minimale Ausgangsangaben vor. Im Jahre 2012 fand man in einem Rüstloch der südlichen Hochwand der Kirche ein Fragment eines verkohlten Auslegers. Die Radiokarbonprobe ergab als kalibriertes Alter mit einer Wahrscheinlichkeit von 64\% den Zeitabschnitt von 1630 bis 1670 AD. ${ }^{14}$ Demnach stammt der Ausleger von irgendwelchen Wiederherstellungsoder Renovierungsarbeiten. Da keine weiteren Angaben vorliegen, muss man sich bei der Behandlung des baulichen Werdegangs der Kirche auf die altmodische Detail- und Formanalyse konzentrieren.

\section{DIE PROFILBACKSTEINE DES WESTPORTALS}

Das Westportal der Kirche ist durch eine neuzeitliche Putzschicht bedeckt. Im Jahre 1989 bestand dort die Möglichkeit, eine kleine Zone zu sondieren, und es stellte sich heraus, dass bei der aus Profilbacksteinen errichteten mittelalterlichen Laibung die Fase sich mit der Hohlkehle abwechselt. Getrennt sind diese Formen ziemlich weit und über einen verhältnismäßig langen Zeitraum verbreitet, aber eine solche Kombination kommt in Südestland nur in zwei weiteren Fällen vor. Erstens tritt sie beim Anfangsstadium des Baus des Langhauses der Johanniskirche

12 Villem Raam, „Arhitektuur 13. sajandi teisest verandist kuni 14. sajandi keskpaigani”, Eesti kunst kõige varasemast ajast kuni 19. saj. keskpaigani (Tallinn: Kunst, 1975), 46.

13 Kaur Alttoa, „Urvaste kirik”, Eesti Arhitektuur 4. Tartumaa, Jõgevamaa, Valgamaa, Võrumaa, Põlvamaa, üldtoimetaja Villem Raam (Tallinn: Valgus, 1999), 158.

14 Das Alter beträgt in Radiokarbonjahren 250 \pm 25 (SPb-876). Mit dem kalibrierten Computerprogramm OxCal v4.2.: Christopher Bronk Ramsey, OxCal Version 4.2. The Manual. 2013 (http://c14.arch.ox.ac.uk/oxcal/OxCal.html); r.5; IntCal13 atmosphärische Kurve: (Paula J. Reimer, Edouard Bard, Alex Bayliss, J. Warren Beck, Paul G. Blackwell, Christopher Bronk Ramsey, Pieter M. Grootes, Thomas P. Guilderson, Haflidi Haflidason, Irka Hajdas, Christine Hatté, Timothy J. Heaton, Dirk L. Hoffmann, Alan G. Hogg, Konrad A. Hughen, K. Felix Kaiser, Bernd Kromer, Sturt W. Manning, Mu Niu, Ron W. Reimer, David A. Richards, E. Marian Scott, John R. Southon, Richard A. Staff, Christian S. M. Turney, Johannes van der Plicht. „IntCal13 and Marine13 Radiocarbon Age Calibration Curves 0-50,000 Years cal BP, Radiocarbon", 55(4), 2013, 1111-1150). 
in Dorpat (estnisch: Jaani kirik in Tartu) auf, das auf den Zeitabschnitt von 1321 bis 1328 datiert wird (zum Beispiel beim westlichen Fenster des Nordschiffes). ${ }^{15}$ Die gleiche Formgebung hat man auch in der sogenannten Periode der Hallenkirche bei der Domkirche in Dorpat eingesetzt, als der Nordseite des Langhauses eine Kapellenreihe hinzugefügt wurde, die eine Art eines zusätzlichen Schiffes bildeten. Bei den Laibungen der Kapellenfenster hat man ebenso die Kombination von Fase und Hohlkehle eingesetzt. In den Ostseeländern wurden die ersten Seitenkapellen eines Langhauses beim Lübecker Dom und in der dortigen Marienkirche in den zwanziger Jahren des 14. Jahrhunderts gebaut, in den anderen Städten Norddeutschlands verbreiteten sie sich seit den dreißiger Jahren des 14. Jahrhunderts. ${ }^{16}$ Es ist unglaubwürdig, dass die Idee in Dorpat entstanden sein könnte und sich von dort aus sich in Lübeck und in den anderen Hansestädten ausbreitete - vielmehr verlief die Entwicklung in die umgekehrte Richtung. Somit können die Periode der Hallenkirche bei der Domkirche in Dorpat und zugleich die Fensterlaibungen der Nordseite offensichtlich nicht auf einen früheren Zeitraum als die zwanziger Jahre des 14. Jahrhunderts datiert werden. Diese zwei Fälle in Dorpat stellen natürlich kein ausreichendes Ausgangsmaterial für die Datierung des Hauptportals in Urbs dar. Jedoch dürfte es unwahrscheinlich sein, dass irgendwelche Bauformen die Randgebiete des Bistums erreichten, bevor sie im Zentrum angekommen waren. Von daher müsste es sicher sein, dass zumindest das Portal in Urbs keineswegs im 13. Jahrhundert unterzubringen ist. Jedoch ist es nicht bekannt, ob das Portal gleichzeitig mit den Außenwänden der Kirche errichtet worden ist.

\section{EIN SELTEN VORKOMMENDES STREBEWERK}

Das kurze basilikale Langhaus, die Pfeiler mit einem kreuzförmigen Grundriss und die niedrigen Arkadenbögen stellen die augenfälligsten Kennzeichen der Kirche zu Urbs dar. Hierbei liegt tatsächlich eine Ähnlichkeit zur Jakobskirche in Riga und zur Nikolaikirche in Pernau vor. Jedoch gibt es in Urbs eine äußerst spezifische Lösung, welche die

15 Kaur Alttoa, Tartu Jaani kirik, Kaasautorid Eve Alttoa, Krista Kodres ja Anu Mänd, Eesti kirikud III (Tallinn: Muinsuskaitseamet, 2011), 17, 47.

16 Antje Grewolls, Die Kapellen der norddeutschen Kirchen im Mittelalter. Architektur und Funktion (Kiel: Ludwig, 1999), 24. 


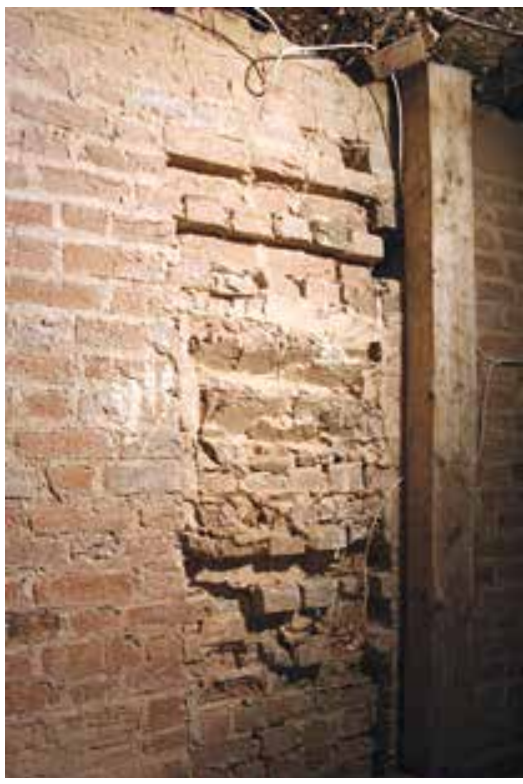

Abb. 6. Die Spuren der Strebemauer auf dem Dachboden des Seitenschiffes der Kirche zu Urbs. Foto von Kaur Alttoa, 2012

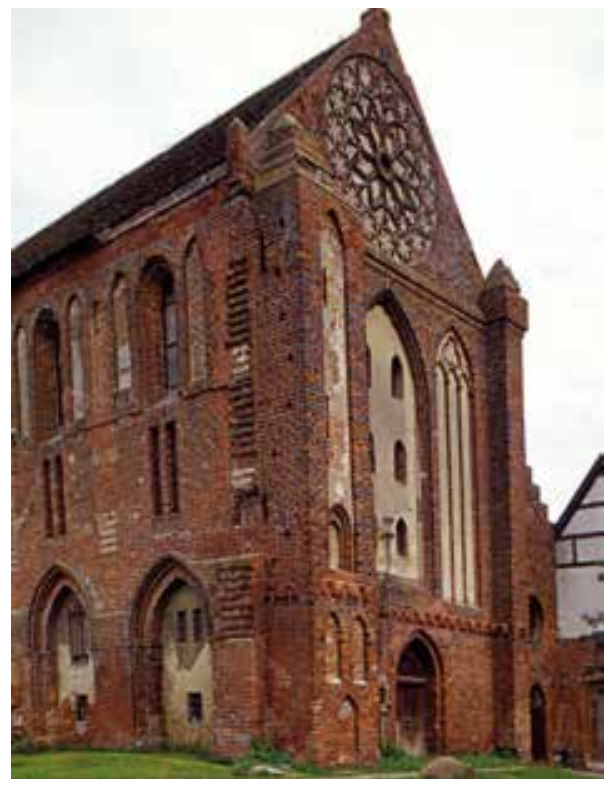

Abb. 7. Die Spuren der Strebemauern auf der Klosterkirche in Colbatz (Kołbacz). Foto von Kaur Alttoa, 2002

Baustatik berücksichtigt und die im Kreis der Rigenser Bauten nicht vorkommt. Nämlich hat man in Urbs, um den Seitenschub des Gewölbes des Mittelschiffes neutralisieren zu können, Strebemauern errichtet, die sich unterhalb der Dächer der Seitenschiffe befanden. ${ }^{17}$ Olev Prints hat behauptet, dass ein solches Strebewerk bereits im 13. Jahrhundert altmodisch gewesen sein soll. ${ }^{18}$ Diese Behauptung erscheint jedoch als nicht korrekt. ${ }^{19}$ Solche Strebemauern hat man noch im 14. Jahrhundert

17 Zuerst hat Armin Tuulse in seinem Tagebuch auf das Motiv in Urbs aufmerksam gemacht. Wissenschaftliches Archiv des Kunstmuseums Tartu (Tartu Kunstimuuseumi teaduslik arhiiv, TKMTA), 3-2-15, 1. 39. Die Behauptung von Voldemar Vaga, dass die Hochwände über Strebepfeiler verfügt haben sollen, ist jedoch nicht stichhaltig (Vaga, Das Problem der Raumform, 26).

18 Olev Prints, „Keskaegne Toomemägi ja hooned”, Toomemägi (Tallinn: Eesti Raamat, 1968), 29.

19 Die Beschäftigung mit dem Thema wird durch die Tatsache gezügelt, dass die zu betrachtende Konstruktion sich nicht in der äußeren Erscheinung der Kirche widerspiegelt - sie wird nämlich durch das Dach des Seitenschiffes verdeckt. So kann man die benötigten Informationen entweder aus der Fachliteratur oder von Objekten, die wenigstens zum Teil in Ruinen liegen, beziehen. 


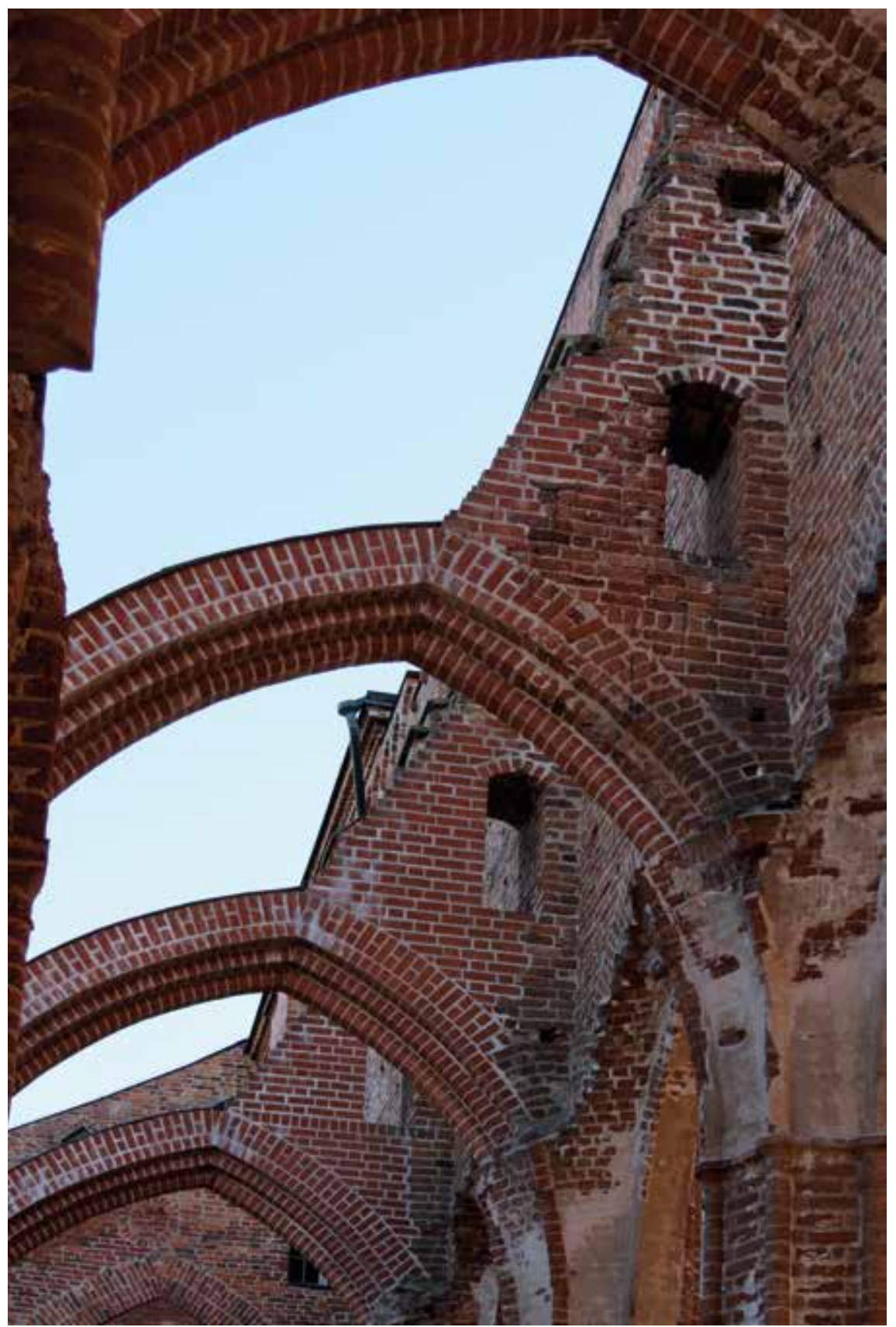

Abb. 8. Die teilweise rekonstruierten Strebemauern in der Domkirche in Dorpat. Foto von Kaur Alttoa, 2013 
in den Backsteinregionen der Ostseeländer eingesetzt. ${ }^{20}$ Deutlich ist das bei der Klosterkirche der Zisterzienser in Colbatz/Kolbatz (polnisch: Kołbacz) zu vernehmen (sie war im Wesentlichen 1307 beendet worden und wurde im Jahre 1347 eingeweiht). ${ }^{21}$

In Alt-Livland ist ein solches Strebewerk nur noch zwei weiteren Fällen bekannt. Erstens aus der dritten (basilikalen) Bauperiode der Domkirche in Dorpat, die auf jeden Fall ins 14. Jahrhundert fällt. Die gleiche Lösung wurde auch in der Johanniskirche in Dorpat ${ }^{22}$ im letzten Drittel des 14. Jahrhunderts eingesetzt, als man sich für die basilikale Raumform entschieden hatte. Bei solch einer spezifischen bautechnischen Lösung ist es kaum wahrscheinlich, dass die Auswahl unabhängig voneinander getroffen worden wäre. Ebenso müsste man annehmen, dass ein solches ingenieurmäßiges Verfahren zuerst das Zentrum des Bistums erreichte und erst danach die Randgebiete und nicht umgekehrt. Das Angeführte stellt die Behauptung, das basilikale Langhaus in Urbs wäre im gesamten Umfang im 13. Jahrhundert gebaut worden, unter ernsthafte Zweifel. Anhand dieser Strebegiebel müsste man eher annehmen, dass die Hochwände nicht vor dem letzten Viertel des 14. Jahrhunderts beendet worden waren.

Die bisherigen Forscher sind von der Voraussetzung ausgegangen, dass die Kirche in ihrem Hauptumfang (zumindest die Außenwände und die Pfeiler) in einem Gang errichtet wurde. Nur die Meinungen darüber, ob die basilikalen Hochwände auch gleichzeitig gebaut wurden oder ob man das Mittelschiff irgendwann angehoben habe, sind auseinandergegangen. Die letzte Vermutung sollte jedoch ausgeschlossen sein. Die Kirche verfügt über stämmige Pfeiler mit einem kreuzförmigen Grundriss und über niedrige Arkadenbögen und sie konnten keineswegs

20 Die zu untersuchende Konstruktion unterscheidet sich ein wenig von den unter dem Seitenschiffdach befindlichen verborgenen Strebebögen. Eine solche Lösung hat man bei den Klosterkirchen der Zisterzienser sowohl in Chorin als auch in Bad Doberan eingesetzt. (Wolfgang Erdmann, Zisterzienser-Abtei Chorin (Königstein im Taunus: Hans Köster Verlagsbuchhandlung KG, 1994), 50; Wolfgang Erdmann, Zisterzienser-Abtei Doberan (Königstein im Taunus: Hans Köster Verlagsbuchhandlung KG, 1995), 33, 92).

21 Zygmunt Świechowski, „Kościół cysterski w Kołbaczu”, Sztuka Pomorza Zachodniego (Warszawa: Państwowe wydawnictwo naukowe, 1973), 24.

22 Zuerst bemerkte dies Jaan Tarmu, Tartu Jaani kiriku ehitusajalugu. Magisterarbeit, Manuskript in der Bibliothek der Universität Tartu (Tartu, 1941), 28. In Bezug auf das Strebewerk in Urbs weist auch Villem Raam auf die Zisterzienser und auf das Vorbild der Johanniskirche hin, aber seiner Meinung nach war die Johanniskirche bereits am Anfang des 14. Jahrhunderts fertig gestellt worden. Villem Raam, „Keskaegsete linnuste ja kirikute arengujooni Eestis”, Ehitus ja Arhitektuur 1/2 (1985), 26. 
zu einer Hallenkirche gehört haben. Jedoch sollte darauf aufmerksam gemacht werden, dass im Unterschied zu den meisten Basiliken Livlands die Hochwände in Urbs nicht durch Lisenen oder durch Wandpfeiler gegliedert sind, um die Gewölbe und die Gurtbögen zu stützen. ${ }^{23}$ Diese Tatsache suggeriert zuerst den Gedanken, dass in dem ursprünglich gewölbelosen Mittelschiff in Urbs eigentlich irgendwelche niedrigeren Hochwände vorhanden gewesen sein könnten, die für eine Stufenhalle charakteristisch sind. Der Abschnitt der Hochwände mitsamt dem für die Strebemauern errichteten Zahnwerk, das auf dem Dachboden zu sehen ist, ist jedoch homogen. Aufgrund dessen sollte man folgern können, dass die Hochwände angefangen mit den Pfeilern bis hin zu den Fenstern des Lichtgadens gemeinsam gebaut worden sind und dass eine gewölbte Basilika geplant gewesen war. Eine Frage an sich ist aber, wie die Hochwände und die Außenwände der Kirche in Beziehung gesetzt worden sind. Als einzige könnten hier in der Zukunft umfangreiche Sondagen im westlichen Teil der Kirche Klarheit schaffen.

\section{DIE ARCHITEKTONISCHEN GEFÄHRTEN DES GLEICHEN TYPS DER KIRCHE ZU URBS}

Die Behandlungen der Architektur der Kirche zu Urbs haben sich bisher hauptsächlich auf Analogien gestützt. Deshalb wäre es zweckmäßig zu überprüfen, ob und welche Unterstützung diese Vergleichsobjekte beim jetzigen Forschungsstand bieten, um die Baugeschichte der Kirche aufzuklären. Als mögliche Vorbilder, aber auch als Parallelbeispiele sind die Nikolaikirche in Pernau, die Jakobskirche in Riga und die Bartholomäuskirche in Rujen erwähnt worden.

\section{DIE NIKOLAIKIRCHE IN PERNAU}

Die Nikolaikirche in Pernau brannte 1944 im Zweiten Weltkrieg nieder. Zehn Jahre später wurden die Ruinen gesprengt, ohne sie sogar ordentlich dokumentiert zu haben. Demnach ist das Material, das die Nikolaikirche in Pernau widerspiegelt, äußerst lückenhaft

23 Auf eine ähnliche Art und Weise ohne Gliederungen sind auch die Hochwände der Kirchen in Wolmar (lettisch: Valmiera) und in Rujen gestaltet. 
und oberflächlich. ${ }^{24}$ In ihrer endgültigen Form war die Stadtkirche von Pernau eine dreijochige Basilika, für die Pfeiler mit kreuzförmigem Grundriss und niedrige Arkadenbögen charakteristisch waren. Verhältnismäßig außergewöhnlich für die mittelalterliche Architektur Estlands gab es im Langhaus Sterngewölbe. Bezüglich der Baugeschichte der Kirche hat man sehr unterschiedliche Standpunkte vorgebracht. Weiter oben wurde bereits erwähnt, dass Alfred Vaga dort ursprünglich eine Hallenkirche vermutete, die später nach dem Beispiel der Jakobskirche in Riga zu einer Basilika umgebaut worden war. ${ }^{25}$ Voldemar Vaga behauptete, indem er seine These über die Dominanz der basilikalen Raumform in Riga verfolgte, dass die Nikolaikirche in Pernau bereits im 13. Jahrhundert als eine Basilika gebaut worden war. Das Langhaus erhielt neue Sterngewölbe im Zeitraum von 1524 bis 1529. ${ }^{26}$ Villem Raam hat dahingegen vermutet, dass es sich bei dem betrachteten Langhaus ursprünglich um keine Hallenkirche und auch um keine Basilika gehandelt hatte, sondern um eine Stufenhalle oder Pseudobasilika mit verhältnismäßig niedrigen Hochwänden, die am Anfang des 16. Jahrhunderts zu einer Basilika umgebaut und gleichzeitig gewölbt wurde. ${ }^{27}$

Wenigstens der Bau der Gewölbe des Langhauses der Nikolaikirche in Pernau ist genau dokumentiert. Die Kirche brannte im Jahre 1524 und 1529 erhielt sie neue Gewölbe, wobei der Meister mitsamt den Gehilfen aus Dorpat anreist war. ${ }^{28}$ Es sticht jedoch ins Auge, dass die neuen Sterngewölbe sich sehr schlecht an die Wandvorlagen anpassten und ihre Gliederung nicht berücksichtigten. Anhand solch eines Bildes kann man mit höchster Wahrscheinlichkeit den Schluss ziehen, dass die basilikalen Hochwände - auch ihre obere Teile - während der Errichtung der Gewölbe im Jahre 1529 bereits vorhanden gewesen waren.

24 Der Autor erinnert sich dankbar an Villem Raam, der die von ihm gesammelten Fotos (in der Mehrzahl jedoch Reproduktionen) von den Ruinen der Kirche zur Verfügung gestellt hatte.

25 Waga, Eesti kunsti ajalugu I, 116, 118.

26 Vaga, Das Problem der Raumform, 22-23.

27 Raam, „Arhitektuur 13. sajandi teisest verandist kuni 14. sajandi keskpaigani”, 44; Raam, „Keskaegsete linnuste ja kirikute arengujooni Eestis”, 26. Die Konzeption Villem Raams wurde zum ersten Mal von Elsbet Parek vorgestellt: Elsbet Parek, Pärnu sajandeis. Ehituskunstiline ülevaade (Tallinn: Eesti Raamat, 1971), 13.

28 Pärnu linna ajaloo allikad 13.-16. sajandini. I osa / Quellen zur Geschichte der Stadt Pernau 13.-16. Jahrhundert. Bd. I, zusammengestellt von Inna Põltsam und Aldur Vunk (Pärnu: Pärnu Linnavalitsus, 2001), 279. Siehe auch Inna Põltsam, „Zur Baugeschichte von Neu-Pernau in der Amtszeit des Bürgermeisters Johann vom Lynthem (1519-1548)", Zeitschrift für OstmitteleuropaForschung, 50, H. 3 (2001), 380. 

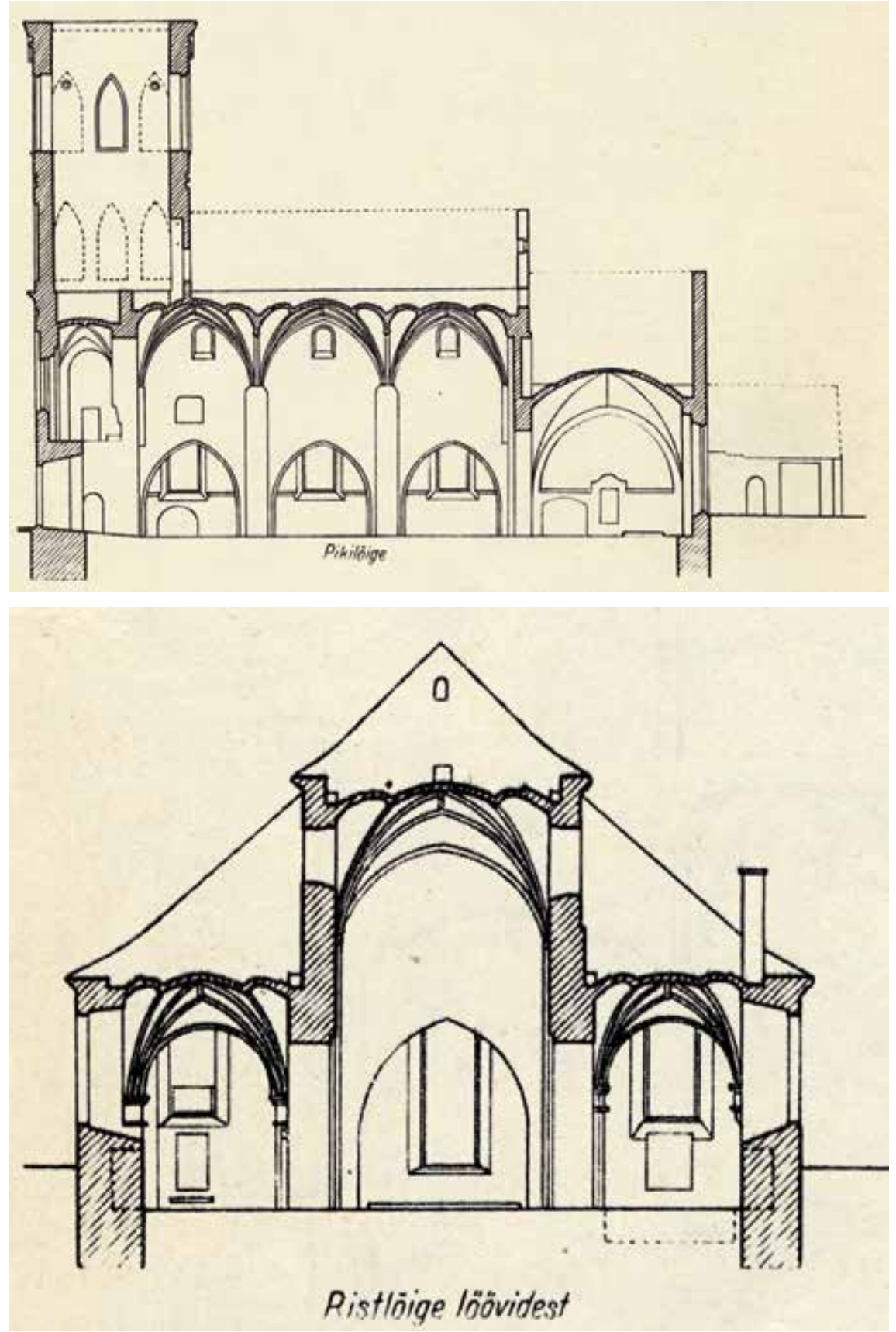

Abb. 9, 10. Die Nikolaikirche in Pernau. Vermessen von Jaagup Linnakivi 1945. Elsbet Parek, Pärnu sajandeis, 15-17 


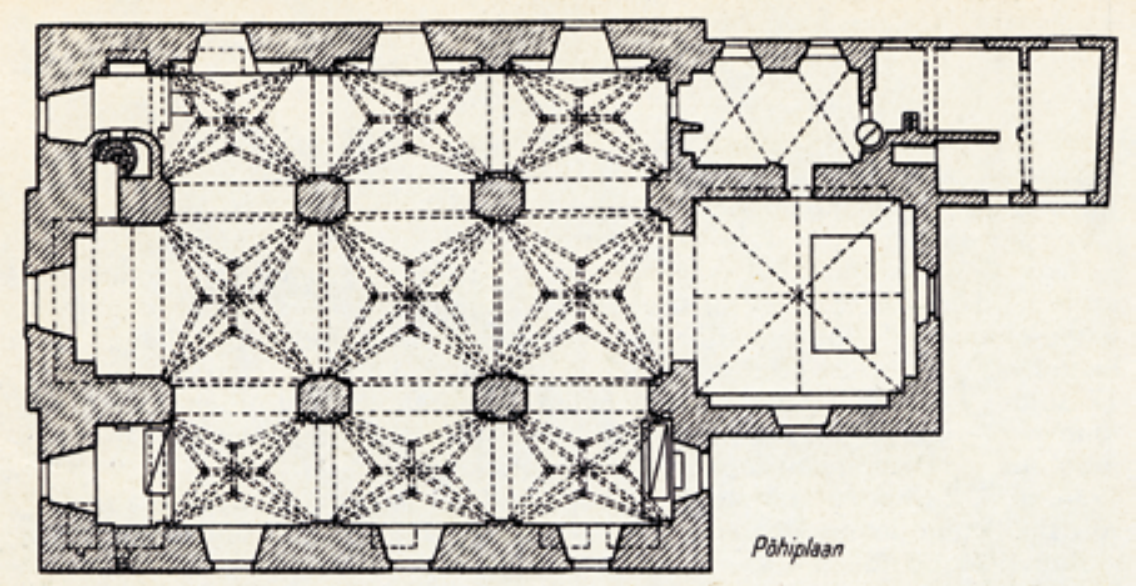

Abb. 11. Die Nikolaikirche in Pernau. Vermessen von Jaagup Linnakivi 1945. Elsbet Parek, Pärnu sajandeis, 15-17

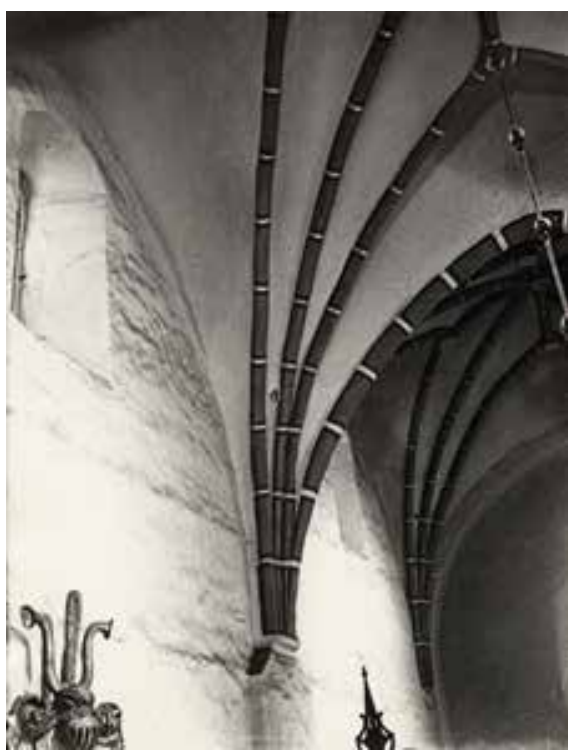

Abb. 13. Das Mittelschiff der Nikolaikirche in Pernau. Fotos von Armin Tuulse, 1943

Anhand der Fotos, die nach dem Brand gemacht worden sind, kann man mit ziemlich hoher Wahrscheinlichkeit den Schluss ziehen, dass die Hochwände mitsamt den Pfeilern gemäß einem einheitlichen Plan errichtet worden sind. Es sind keine Zeichen vorhanden, die auf unterschiedliche bauliche Aufschichtungen oder auf Umbauten hinweisen würden. Die Pfeiler und die Hochwände waren aus Backsteinen errichtet worden, wobei im Mauerwerk der Läufer-Binder-Verband eingesetzt worden war. Backsteine waren ebenso bei der Errichtung des Chorraums verwendet worden - dabei auch im Falle der Wand, die sich beim Triumphbogen befand. Die Nord- und Südwände des Langhauses waren dahingegen aus Feldsteinen gelegt, während in geringerem Umfang auch Kalksteine und Backsteine verwendet worden 


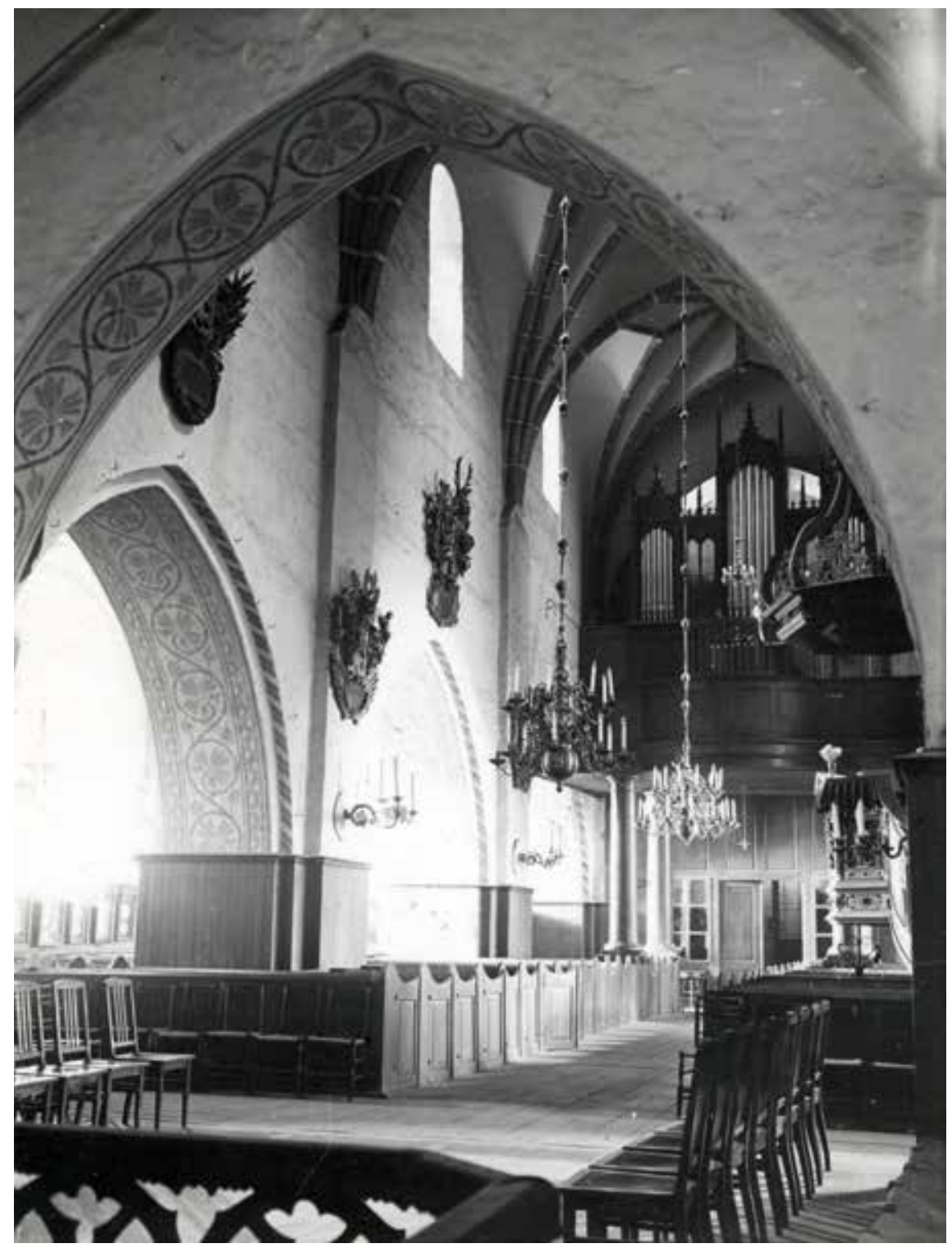

Abb. 12. Das Mittelschiff der Nikolaikirche in Pernau. Fotos von Armin Tuulse, 1943

waren. Diese Beobachtungen stellen die bisherigen Vermutungen über die Nikolaikirche in Pernau ernsthaft in Frage. ${ }^{29}$

29 Eesti arhitektuur (Estnische Architektur) vorgelegt wurde (Alttoa, „Nikolai kirik”, 101-102). 

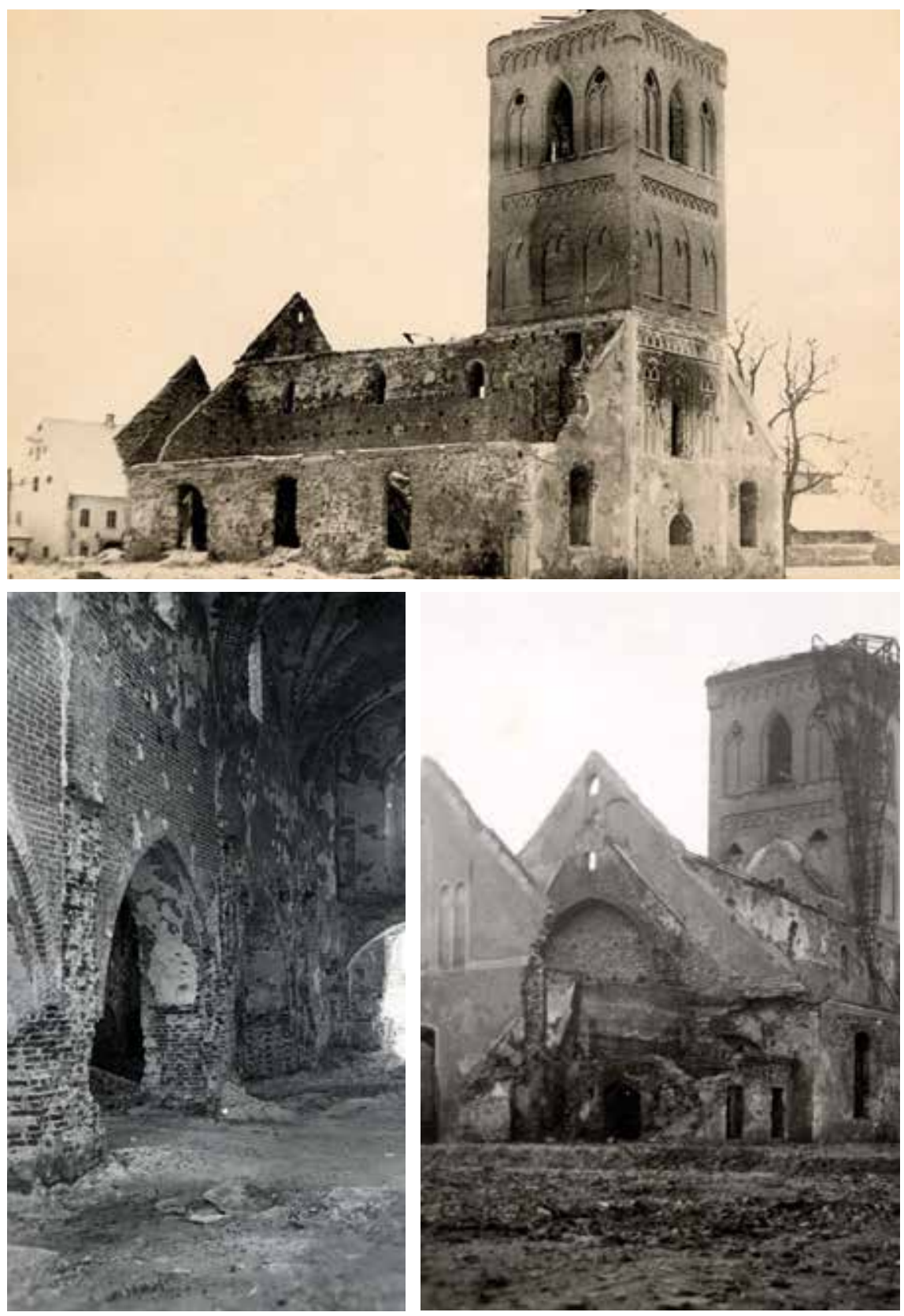

Abb. 14, 15. Die Ruinen der Nikolaikirche in Pernau im Jahr 1951. Anonyme Fotos

Abb. 16. Die Ruinen der Nikolaikirche in Pernau nach dem Brand des Jahres 1944. Anonymes Foto 
Das augenfälligste Detail des Chorraumes stellte eine geräumige Nische in der östlichen Wand dar, welche die Altarzone betont. ${ }^{30}$ Es handelt sich um ein verhältnismäßig selten auftretendes Element in der mittelalterlichen Architektur Estlands. Bei keinem der architektonischen Gefährten des gleichen Typs der Nikolaikirche in Pernau tritt ein solches Element auf. Wie konnte aber eine solche Ostnische Pernau erreichen - darüber kann man nur Vermutungen anstellen. Eine der ersten solchen Lösungen steht in der Kirche in Holme/Alt-Kirchenholm (lettisch: Vecsalaspils) in der Nähe von Riga. Auf eine ähnliche Art und Weise ist auch die Ostwand der Domkirche in Hapsal (estnisch: Haapsalu) gestaltet. Die Kirche in Holme und die in Hapsal sind auch durch eine ähnliche Planlösung miteinander verbunden. In beiden Fällen handelt es sich um dreijochige Saalkirchen ohne einen selbständigen Altarraum. In Anbetracht der gemeinsamen Züge muss man die Möglichkeit in Erwägung ziehen, dass die Kirche in Holme auch ein bedeutendes Vorbild bei der Planung der Domkirche in Hapsal gestellt hatte. ${ }^{31}$ Über einen ähnlichen Plan verfügte auch die Domkirche in Alt-Pernau (estnisch: Vana-Pärnu) - somit ist es wahrscheinlich, dass die Ideen sich entlang der Marschroute Holme - Alt-Pernau - Hapsal entlang bewegt haben könnten. Über die Details der Domkirche in Alt-Pernau, darunter über die Gestaltung der östlichen Wand, fehlen allerdings jegliche Angaben. Jedoch kann man in Anbetracht der Analogie der Anlage nicht ausschließen, dass auch dort eine Ostnische vorhanden gewesen war und beim Bau der Stadtkirche von Pernau hat man dieses Motiv aus der Domkirche, die sich am anderen Flussufer befand, oder von ihren Ruinen abgeschaut. ${ }^{32}$

In Anbetracht der zeitlichen Verbreitung des Motivs dürfte der Chor der Nikolaikirche in Pernau nicht später als in den sechziger oder den siebziger Jahren des 13. Jahrhunderts entstanden sein.

Die Unterschiede bei der Materialwahl der Außenwände des Chorraumes und des Langhauses bei der Nikolaikirche scheinen

30 Das Hauptverbreitungsgebiet des Motivs liegt vor allem in Westfalen in den dreißiger und vierziger Jahren des 13. Jahrhunderts. Das Thema der Ostnische wurde genauer behandelt bei: Villem Raam, „Nelinurkse kooritüübi mõningatest variatsioonidest Eesti keskaegses arhitektuuris”, Kunstiteadus, kunstikriitika, 5 (Tallinn: Kunst, 1983), 88-117.

31 Kaur Alttoa, „Mõningaid Valjala ja Kaarma kiriku ehitusloo probleeme”, Saaremaa Muиseumi kaheaastaraamat 2001-2002 (Kuressaare, 2003), 22-25.

32 Kaur Alttoa, „Kui piiskop polnud veel Haapsallu jõudnud”, Läänemaa muuseumi toimetised, XVI (Haapsalu, 2013), 22. 
darauf hinzuweisen, dass sie nicht gleichzeitig entstanden sind. Kaum zu glauben, dass zu einem Chorraum, der auf solch eine stabile Art und Weise errichtet worden ist, im Laufe eines längeren Zeitraumes nur ein provisorischer Gemeinderaum aus Holz hinzukam. Demnach könnte man voraussetzen, dass das bekannte dreijochige Langhaus über irgendeinen Vorgänger verfügt hatte. ${ }^{33}$ Aufgrund der Unterschiedlichkeit des Baumaterials bei den verschiedenen Teilen des Langhauses würde ich es wagen zu behaupten, dass die Außenwände und die Hochwände des Langhauses nicht aus einer Kulturschicht entstammen, oder anders ausgedrückt, die Hochwände sind jünger. Die Lisenen, welche die Außenwände gliedern, weisen darauf hin, dass bereits damals, als man mit dem Langhaus angefangen hatte, auch das Vorhaben bestand, Gewölbe zu errichten. Wie sah aber die geplante Raumform aus: eine Basilika, eine Hallenkirche oder irgendeine Zwischenversion - dies ist anhand der uns bekannten Mauersubstanz nicht herauszufinden. Ihre basilikale Allgemeinform erhielt die Kirche erst während der dritten, größeren Bauperiode, als die Hochwände errichtet wurden. Somit stellte die Errichtung der Sterngewölbe im Jahre 1529 bereits die vierte größere Bauetappe im Werdegang der Kirche dar.

Für eine Datierung der einzelnen Bauperioden des Langhauses liegen keine sicheren Anhaltspunkte vor. In den Urkunden ist die Rede von einer Errichtung des Dachstuhls um das Jahr 1420. Anhand dessen hat Heinrich Laakmann vermutet, dass damals ein umfangreicherer Umbau der Kirche stattgefunden hatte. ${ }^{34}$ Der Bau eines Daches muss allerdings nicht zwangsläufig mit einem umfassenden Umbau des Mauerwerks der Kirche verbunden sein. Jedoch war während des zu betrachtenden Zeitabschnitts das Thema der Basiliken in den hiesigen Hansestädten akut (siehe weiter unten). So erscheint es als nicht ausgeschlossen, dass man sich auch in Pernau in den zwanziger Jahren des 15. Jahrhunderts für die damals moderne Raumform entschieden hatte und die Kirche neue Hochwände erhielt. Es handelt sich aber nur um eine Möglichkeit, der keine ordentliche Beweisführung zugrunde liegt.

33 In Anbetracht von analogen Bauten mit einer Ostnische kann die Möglichkeit nicht ausgeschlossen werden, dass es sich bei der Nikolaikirche in Pernau ursprünglich sogar um eine von außen ungegliederte Saalkirche gehandelt hatte. Es ist eine Möglichkeit, die jedoch nicht mehr nachgeprüft werden kann.

34 Heinrich Laakmann, „Das mittelalterliche Kirchenwesen Neu-Pernaus”, Sitzungsberichte der Gelehrten Estnischen Gesellschaft 1922 (Dorpat, 1923), 128. 


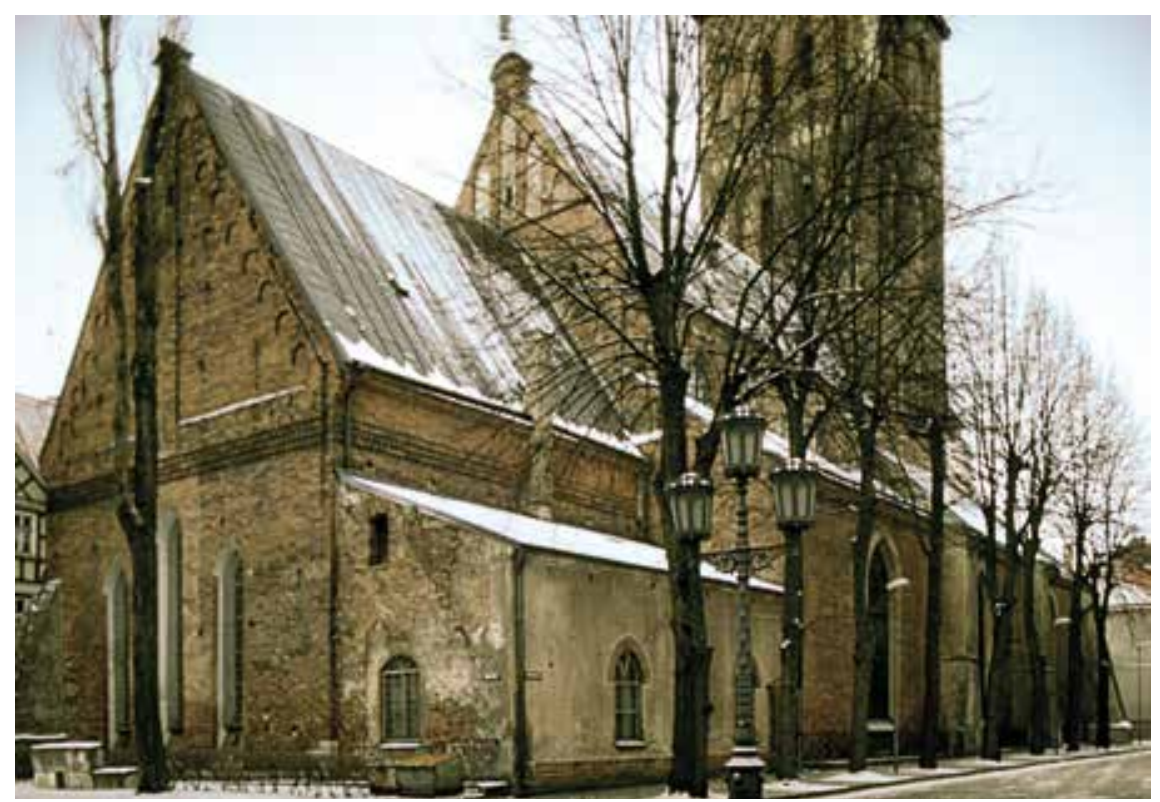

Abb. 17. Die Jakobskirche in Riga. Foto von Kaur Alttoa, 2001

Demnach ist das Bild der architektonischen Entwicklung der Nikolaikirche in Pernau äußerst lückenhaft und knapp. Immerhin müsste es eindeutig sein, dass die Behauptung, es handle sich um einen die Basilika des 13. Jahrhunderts, im vorliegenden Fall nicht stichhaltig ist.

\section{DIE JAKOBSKIRCHE IN RIGA}

Als der eigentümliche Archetyp in Alt-Livland sowohl für die Kirche in Urbs als auch für die Nikolaikirche in Pernau gilt die Jakobskirche in Riga. In der endgültigen Form handelte es sich um eine Basilika mit zwei Paar Pfeilern und mit niedrigen Arkadenbögen. Die Kirche zählt zu den ältesten in Riga. Urkundlich ist sie das erste Mal am 5. April 1226 erwähnt worden, als Wilhelm von Modena dem Bischof von 


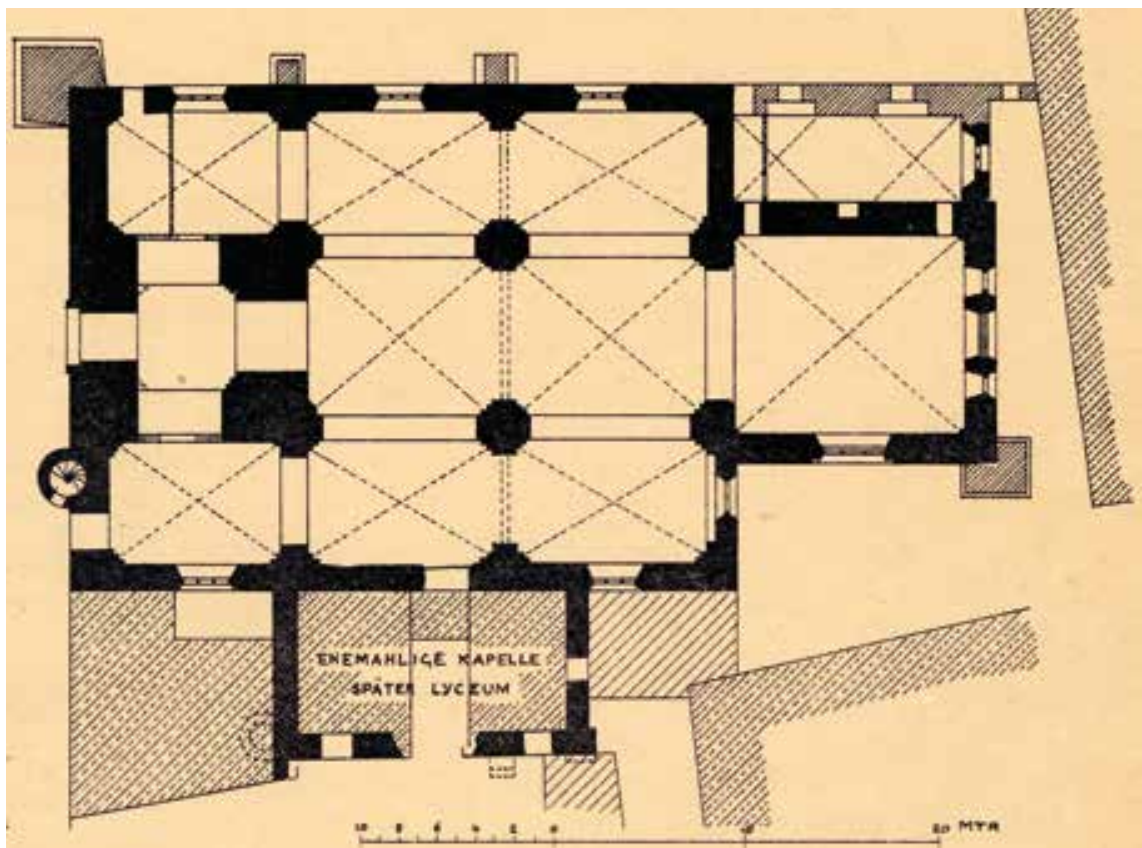

Abb. 18. Grundriss der Jakobskirche in Riga. Neumann, Das mittelalterliche Riga, T. X

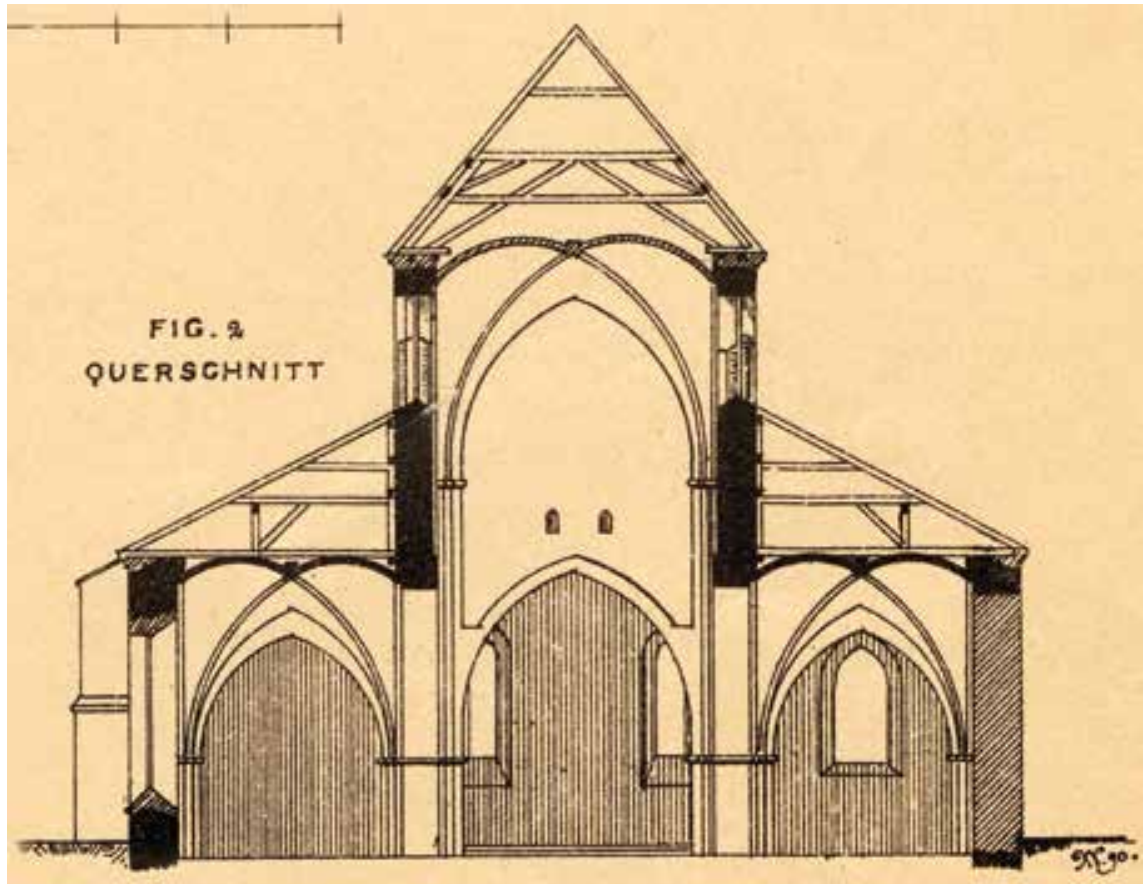

Abb. 19. Querschnitt der Jakobskirche in Riga. Neumann, Das mittelalterliche Riga, T. XI 
Riga das Patronatsrecht über die Jakobskirche verlieh. ${ }^{35}$ Eine wichtige Mitteilung stammt aus dem Jahre 1259, als der Erzbischof Albert Suerbeer dem neugegründeten Zisterzienserinnenkloster die Genehmigung erteilte, die Jakobskirche so lange nutzen zu dürfen, bis ihre eigene Kapelle oder Kirche fertig gebaut wird. ${ }^{36}$

Über die bauliche Entwicklung der Kirche hat man unterschiedliche Standpunkte vorgelegt. Die These von Voldemar Vaga von einer im 13. Jahrhundert errichtete Basilika hat man jedoch ziemlich einstimmig verworfen. Jānis Zilgalvis hat behauptet, dass die im Jahre 1226 erwähnte Kirche eine dreischiffige Hallenkirche war, die bereits in der Mitte des 13. Jahrhunderts oder am Anfang des 14. Jahrhunderts in eine Basilika umgebaut worden war. ${ }^{37}$ Die bisher einzige veröffentlichte Studie der Kirche stammt von Elite Grosmane, ${ }^{38}$ die sich in Bezug auf die Baugeschichte hauptsächlich auf die handschriftliche Untersuchung der Jakobskirche in Riga von Robert Malvess aus dem Jahre 1976 stützt. Danach

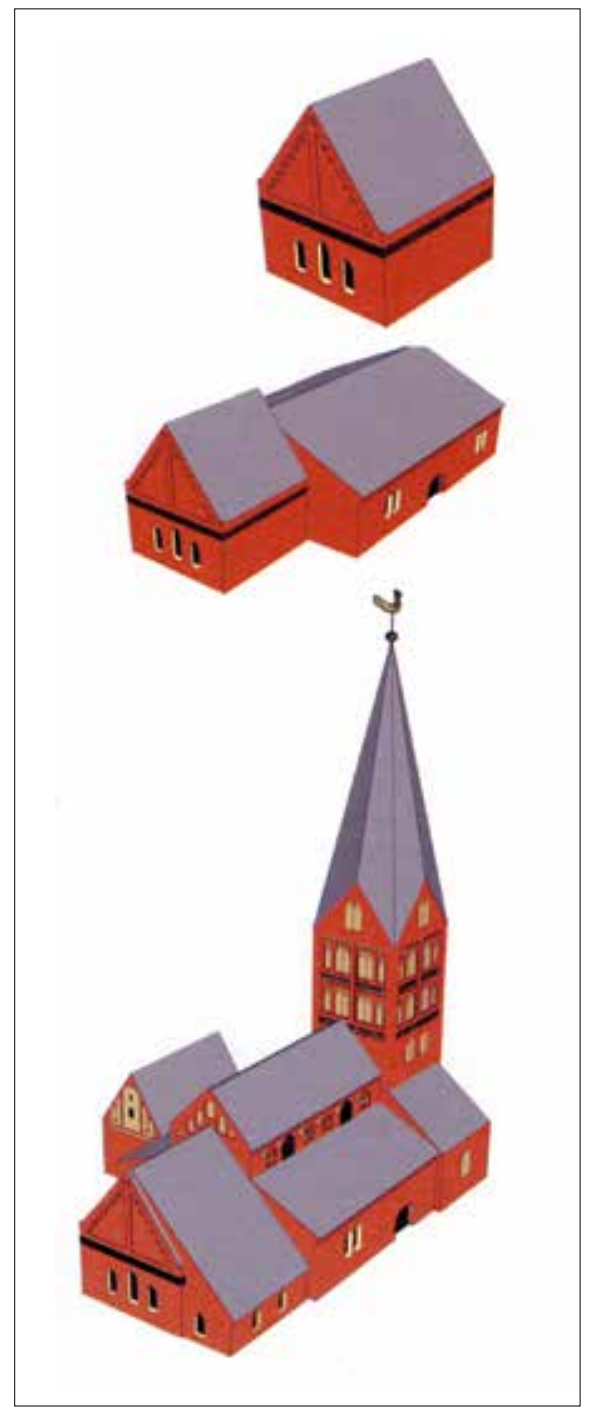

Abb. 20. Die bauliche Entwicklung der Jakobskirche in Riga nach Elite Grosmane: ungefähr 1220, 1260 und zu Anfang des 15. Jahrhunderts. Elite Grosmane, “Rīgas Sv. Jēkaba baznica viduslaikos", 31

35 Liv-, Est-und Curländisches Urkundenbuch nebst Regesten, Bd. I, hrsg. von Friedrich Georg von Bunge (Reval: Kluge und Ströhm, 1853), Nr. 82.

36 Ebd., Nr. 336.

37 Jānis Zilgalvis, „St. Jacob’s catholic church”, Eiropa - kopīgs mantojums. Baznīcas Latvijā (Rīga: Valsts kultūras pieminekḷu aizsardzỉbas inspekcija, 1999), 75.

38 Elite Grosmane, „Rīgas Sv. Jēkaba baznica viduslaikos”, Arhitektūra un māksla Rīgā. Idejas un objekti (Rīga: Neptuns, 2004), 9-32. 


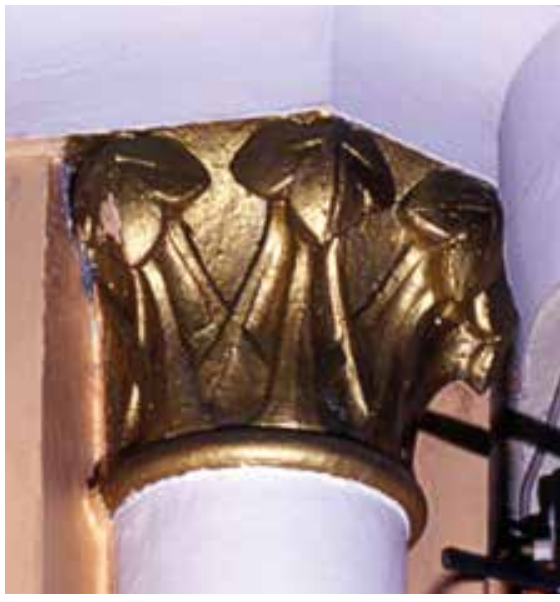

Abb. 21. Kapitell im Chorraum der Jakobskirche in Riga. Foto von Kaur Alttoa, 2003

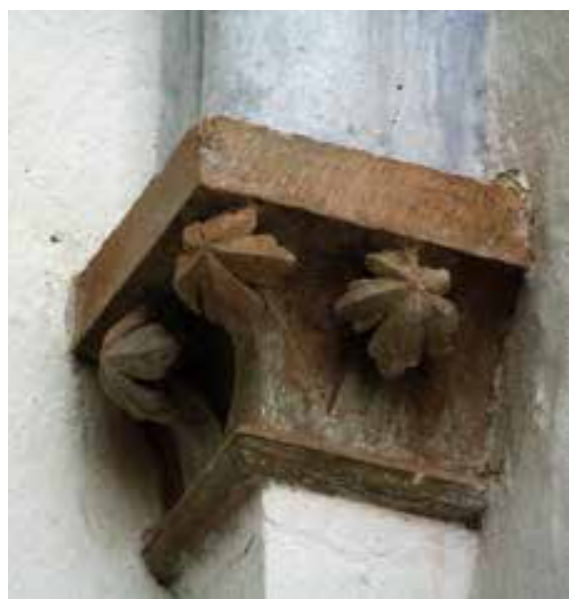

Abb. 22. Kapitell in der Kirche in Goldenbeck. Foto von Kaur Alttoa, 2009

stellt den ältesten Teil der Kirche der aus den zwanziger Jahren des 13. Jahrhunderts stammende Chorraum dar. Bis zu den sechziger Jahren des 13. Jahrhunderts ist das hallenkirchliche Langhaus beendet worden ${ }^{39}$, das am Anfang des 15. Jahrhunderts zu einer Basilika umgebaut wurde.

Den gestalterischen Akzent des Chorraumes der Jakobskirche in Riga bildet die aufsteigende Rundbogenfriese des östlichen Giebels. Offenbar stellt eben dieses archaische Motiv mitsamt der urkundlichen Notiz den Ausgangspunkt für die oben angeführte Datierung dar. Hier verdient jedoch ein Detail nähere Beachtung. Im Chorraum befinden sich Eckkolonetten mit Basis und Kapitell. In einem Fall gibt es dort ein der Frühgotik charakteristisches Knospenkapitell. Auf dem zweiten Kapitell sind anstatt der Knospen Blätter. Dieses Kapitell verfügt über ein sehr nah gelegenes Parallelbeispiel in Westestland - nämlich in der Kirche in Karris (estnisch: Karja) und in der in Goldenbeck (estnisch: Kullamaa). Die Bauzeit der Kirche in Karris ist bis heute noch problematisch. Wahrscheinlich ist die Kirche im dritten Viertel des 13. Jahrhunderts errichtet worden (eher sogar im letzten Viertel), aber auf eine frühere Zeit kann man sie keineswegs datieren. Die Kirche in Goldenbeck und ihr Baudekor sind bisher auf das letzte Drittel des 13. Jahrhunderts datiert

39 Man kann sich keineswegs mit einer Rekonstruktion einverstanden erklären, gemäß der der Dachfirst des dreischiffigen Langhauses niedriger ist als der des Chorraumes. 


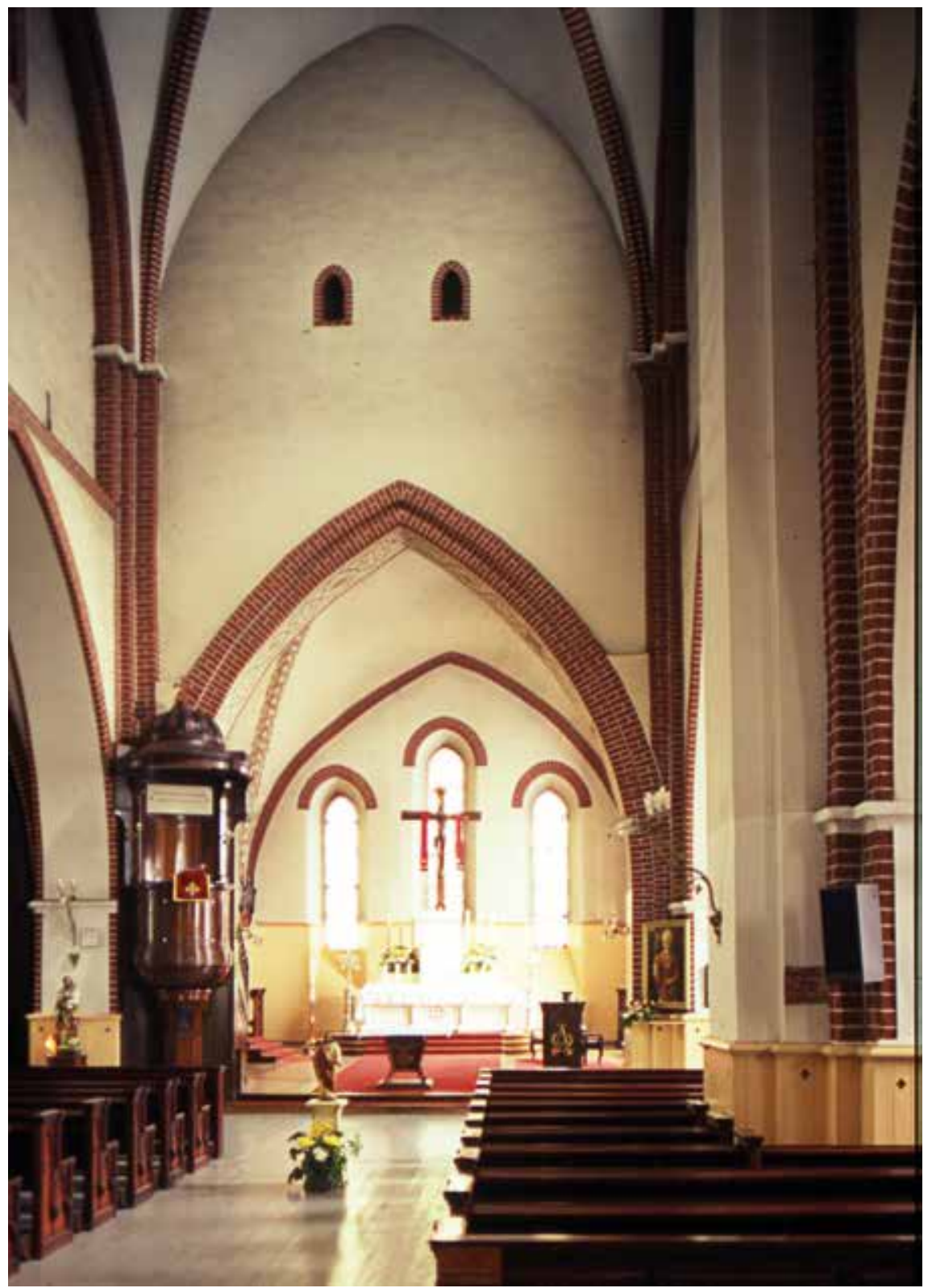

Abb. 23. Die Jakobskirche in Riga. Innenansicht in Richtung Osten. Foto von Kaur Alttoa, 2003 


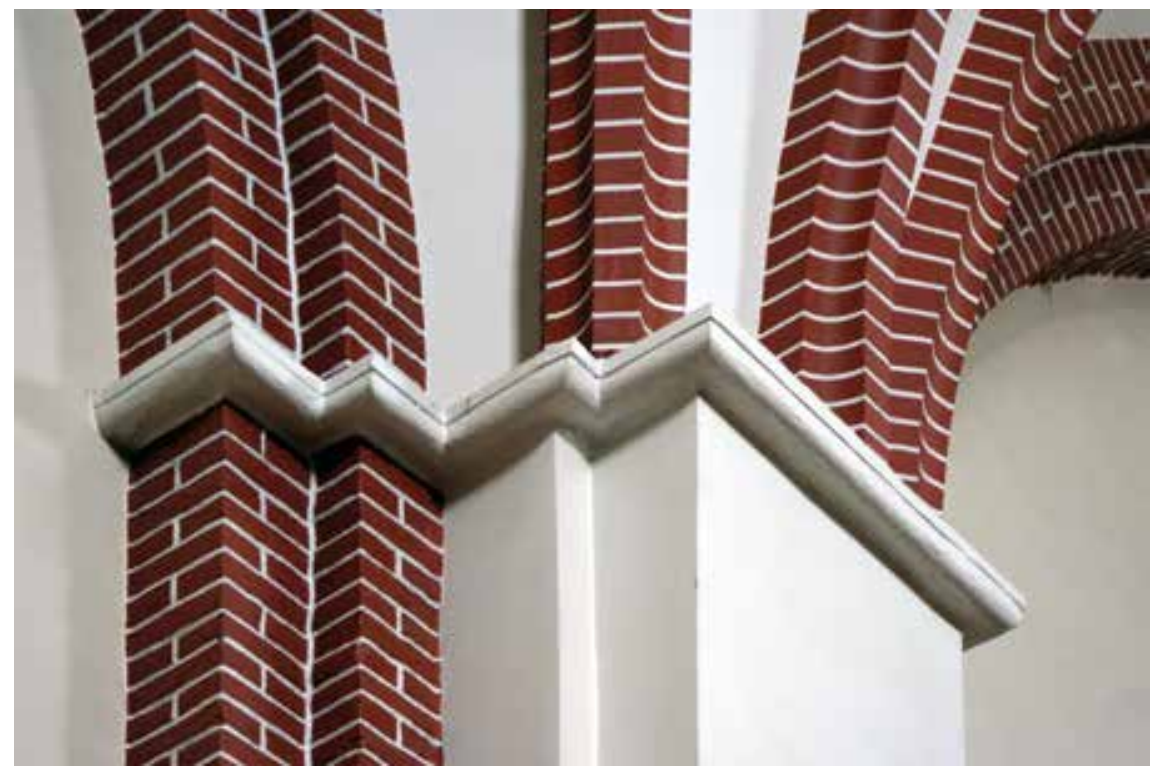

Abb. 24. Wandvorlage und Gewölberippen im Mittelschiff der Jakobskirche in Riga. Foto von Kaur Alttoa, 2008

worden. ${ }^{40}$ Vor dem Hintergrund des Gesagten dürfte es ausgeschlossen sein, dass die frühgotischen Kapitelle der Jakobskirche aus den zwanziger Jahren des 13. Jahrhunderts stammen - wahrscheinlich verschieben sie sich tatsächlich in die zweite Hälfte des Jahrhunderts. Selbstredend besteht die Möglichkeit, dass die Eckkolonetten der früheren Hauptanlage des Chors sekundär hinzugefügt wurden, aber zumindest vorläufig liegen darauf hinweisende Angaben nicht vor. So kann man auch nichts Sicheres über die Bauzeit des Chorraumes behaupten.

Im Langhaus ist besonders die Ostwand des Mittelschiffes ausdrucksvoll, bei der oberhalb des verhältnismäßig niedrigen Triumphbogens die Wand um eine Stufe zurücktritt. Unregelmäßig sind auch die Ecken oberhalb des Triumphbogens gestaltet worden. Für ein solches Bild kann eine Erklärung gefunden werden: die Oberfläche des Triumphbogens war als ein Schildbogen gebaut worden, um das Gewölbe des Mittelschiffes zu stützen. ${ }^{41}$ Also ist hier ein sicheres Zeichen davon vorhanden, dass

40 Villem Raam, „Kullamaa Jaani kirik”, Eesti Arhitektuur 2. Läänemaa, Saaremaa, Hiiumaa, Pärnumaa, Viljandimaa, üldtoimetaja Villem Raam (Tallinn: Valgus, 1996), 24.

41 Kaur Alttoa, „Basilika und Hallenkirche im Backsteingebiet Alt-Livlands”, Sakrale Kunst im Baltikum. Baltische Seminare, 6 (Lüneburg: Carl-Schirren Gesellschaft, 2008), 22. 


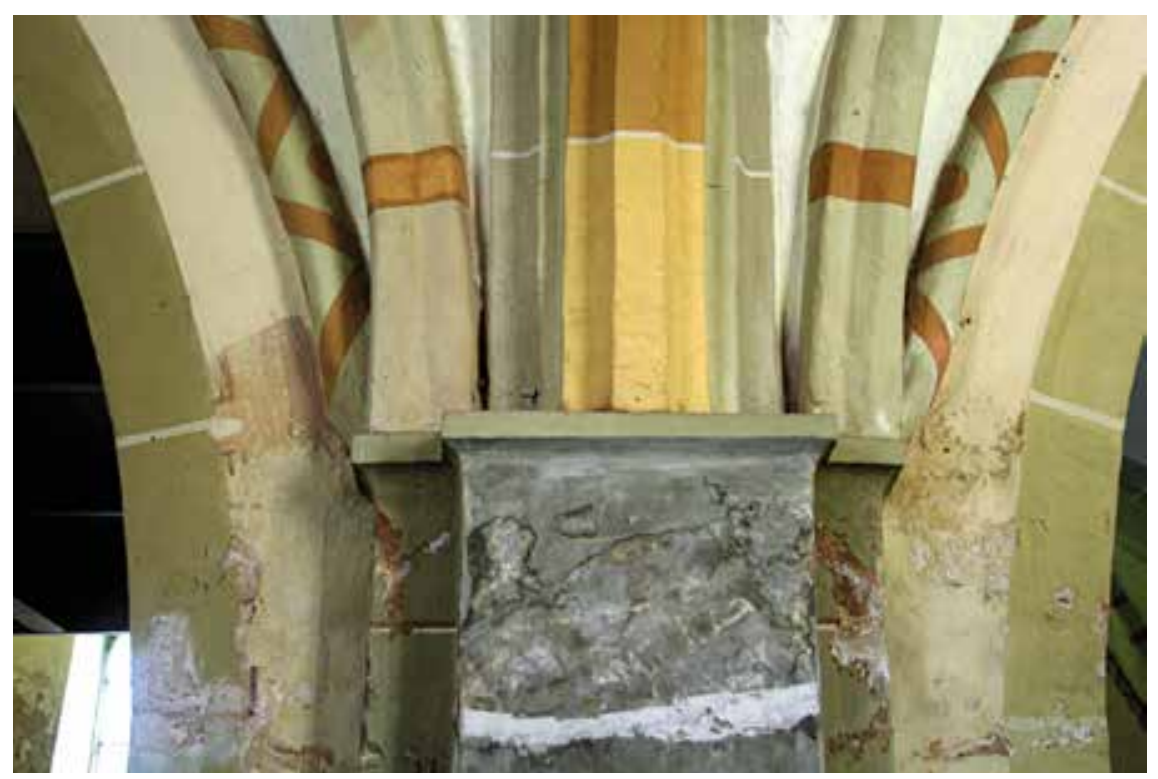

Abb. 25. Wandvorlage und Gewölberippen im Mittelschiff der Kirche in Wenden. Foto von Kaur Alttoa, 2008

während man mit der Errichtung des Langhauses begonnen hatte, eine Hallenkirche oder eine Stufenhalle, jedenfalls keine Basilika geplant war. Sowohl die Stufe des Schildbogens als auch die Wandvorlagen der Außenwände bezeugen eindeutig, dass das Vorhaben bestanden hatte, die Kirche mit Gewölben auszustatten. Jedenfalls sind die Außenwände des Langhauses verhältnismäßig frühen Ursprungs darauf weisen die Überbleibsel der Fensterpaare mit Rundbogen hin, die den Fenstern des Chorraumes ähneln. Zusätzlich hat man im Falle des Nordportals, die aus der Zeit der Hallenkirche stammt, eine eigenartige technologische Verfahrensweise eingesetzt: die Oberflächen der Backsteine sind geriefelt - nachdem die Backsteine gebrannt wurden, hat man auf die Steinoberfläche diagonale Furchen eingehauen. Laut Elite Grosmane, die darauf aufmerksam gemacht hat, handelte es sich um ein Verfahren, das nur für einen kurzen Zeitraum in der ersten Hälfte des 13. Jahrhunderts im Einsatz gewesen war. ${ }^{42}$ In Wirklichkeit ist die Riefelung 
jedoch etwas länger verbreitet gewesen. ${ }^{43}$ In Alt-Livland ist eine solche Oberflächenbearbeitung an zwei Fällen bekannt: in der Sockelzone des Langhauses der Domkirche in Dorpat ${ }^{44}$ und bei der Fensterlaibung eines Raumes der Burg in Odenpäh (estnisch: Otepää). ${ }^{45}$ Beide sind bisher nicht genauer datiert worden.

Bei der Datierung des ursprünglichen Langhauses der Jakobskirche in Riga ist die bereits erwähnte Information aus dem Jahre 1259 von Bedeutung, als die Zisterzienserinnen die Erlaubnis erteilt bekamen, die Kirche benutzen zu dürfen. Demnach musste die Kirche in irgendeiner Form bereits fertig gestellt worden sein - offenbar stammen aus der Zeit zumindest die Außenwände des Langhauses.

In der Literatur ist mehrfach auch die Behauptung aufgestellt worden, dass die Kirche im 15. Jahrhundert zur Basilika umgebaut wurde. Es sind aber keine Begründungen dieses Standpunktes vorgelegt worden. Offensichtlich handelt es sich um eine Ansicht Wilhelm Neumanns, ${ }^{46}$ welche die späteren Forscher mechanisch übernommen haben. Gleichzeitig hat man aber a priori vorausgesetzt, dass mit dem Umbau zur Basilika auch die Wölbung einherging. Nur Hans Thümmler hat darauf hingewiesen, dass die Rippengewölbe mit gebusten Kappen nicht zu den Vorlagen der Hochwände passen. ${ }^{47}$

In der Wirklichkeit ist hier das Bild doch etwas komplizierter. Die Hochwände der Jakobskirche sind durch mehrstufige Wandpfeiler gegliedert. Sie bezeugen, dass während der Errichtung der Hochwände die Wölbung vorgesehen worden war. Die geplante Struktur des Gewölbes mit breiten Gurtbögen und mit Schildrippen ist deutliche vernehmbar. Womöglich war die Errichtung eines Gratgewölbes geplant gewesen.

43 Matthias Zahn, „Mittelalterliche Backsteinfarbigkeit und Oberflächenstrukturen an Beispielen in Nordostdeutschland", Technik des Backsteinbaus im Europa des Mittelalters, hrsg. von Johannes Cramer und Dorothée Sack. Berliner Beiträge zur Bauforschung und Denkmalpflege, 2 (Petersberg: Michael Imhof Verlag, 2005), 34.

44 Kaur Alttoa, „Tartu toomkiriku pikihoone kujunemisest”, Töid kunstiteaduse ja-kriitika alalt, 3 (Tallinn: Kunst 1980), 89-90.

45 Olev Prints, Otepää piiskopilinnuse varemete 1960. a. konserveerimistööde aruanne, Handschrift im Archiv des Estnischen Denkmalschutzamtes (Tallinn, 1962), 40.

46 Wilhelm Neumann, Das mittelalterliche Riga. Ein Beitrag zur Geschichte der norddeutschen Baukunst (Berlin: Julius Springer, 1892), 25. Im Unterschied zu den anderen Autoren haben Karl Heinz Clasen und Hans Thümmler angeboten, dass der Umbau zur Basilika im 14. Jahrhundert stattgefunden haben könnte: Karl Heinz Clasen, „Grundlagen baltendeutscher Kunstgeschichte”, Baltische Lande I. Ostbaltische Frühzeit, hrsg. von Albert Brackmann und Carl Engel (Leipzig: S. Hirzel, 1939), 459; Hans Thümmler, „V. Vaga, Das Problem der Raumform in der mittelalterlichen Baukunst Lettlands und Estlands" (Rezension), Zeitschrift für Kunstgeschichte, Bd. 25, H. 3/4 (München-Berlin, 1962), 284. 47 Thümmler, „V. Vaga, Das Problem der Raumform”, 284. 
Bei der Wölbung des Langhauses wurden diese Pläne jedoch nicht umgesetzt. Die Gurtbögen sind stattdessen durch Querrippen ersetzt worden. Die Gewölbeelemente „sitzen“ zum Teil unlogisch und unsymmetrisch auf den Wandpfeilern ${ }^{48}$ und ein Teil der Elemente der zuletzt erwähnten hat keine Anwendung gefunden. Hieraus kann man den Schluss ziehen, dass die Errichtung der Gewölbe eine selbständige Etappe im Werdegang des Langhauses darstellt hatte und das Langhaus der Jakobskirche in Riga seine endgültige Form als Ergebnis von drei größeren Bauetappen erhielt.

Um die einzelnen Bauetappen absolut genau datieren zu können, dafür fehlen zurzeit die Anhaltspunkte. Jedoch muss man auf die Gestaltung der Gewölberippen hinweisen. In der Backsteingegend Estlands kommt solch eine Form nicht vor, die gleichen Rippenprofile gibt es aber in der Jakobskirche in Wenden (lettisch: Cēsis). Auch dort befolgt das Gewölbesystem des Mittelschiffes nicht die breiten zweistufigen Wandvorlagen der Hochwände - offensichtlich sind die Gewölbe nicht zusammen mit den Hochwänden errichtet worden. Bisher haben sich die Forscher mit der Frage begnügt, aus welcher Zeit die basilikale Form der Kirche denn stammt. Hierbei bilden die Experten zwei Lager: Voldemar Vaga ${ }^{49}$ folgend wurde behauptet, dass all das aus dem 13. Jahrhundert stammt, ${ }^{50}$ oder dann die These von Wilhelm Neumann ${ }^{51}$ fortsetzend, dass es sich um Umbauten des 15. Jahrhunderts handele. ${ }^{52}$ Die Tatsache, dass die Errichtung der Gewölbe eine eigenständige Bauetappe gebildet hatte und die Frage, wann sie gebaut wurden - diese Fragestellungen haben im allgemeinen Fall nicht auf der Tagesordnung gestanden. ${ }^{53}$ Womöglich liefert eine nähere Analyse der Gewölbe mit dem

48 Die Verschiebung der Gewölberippen ist auch verständlich, denn im entgegengesetzten Fall hätte man solche Gewölbe errichten müssen, die in ihrem unteren Teil über eine augenfällig unregelmäßige Konfiguration verfügt hätten.

49 Vaga, Das Problem der Raumform, 17-18.

50 Beispielsweise Zilgalvis, „St. Jacob`s catholic church”, 75, Nr. 14: Die Kirche wurde im Zeitraum vom 1281 bis 1284 errichtet.

51 Neumann, Das mittelalterliche Riga, 25.

52 Siehe Andris Caune, Ieva Ose, Latvijas viduslaiku mūra baznīcas 12. gs. beigas - 16. gs. sākums. Enciklopēdija (Rīga: Latvijas vēstures institūta apgāds, 2010), 123-124.

53 Als wahrscheinlich Einziger hat Jurijs Vassiljevs die Bauzeit der Gewölbe ungefähr in der Mitte des 14. Jahrhunderts vermutet. Sein einziges Argument besteht in der einzelnen Hauptkonsole im östlichen Teil der Kirche (Kaur Alttoa, Jurijs Vasiljevs und Jonas Minkevičius, Kunstdenkmäler Baltische Staaten. Estland. Lettland. Litauen (Leipzig: Edition Leipzig, 1992), 358). Es handelt sich um eine ziemlich stilisierte Skulptur, die sogar mit der Genauigkeit eines Jahrhunderts schwer zu datieren ist. 


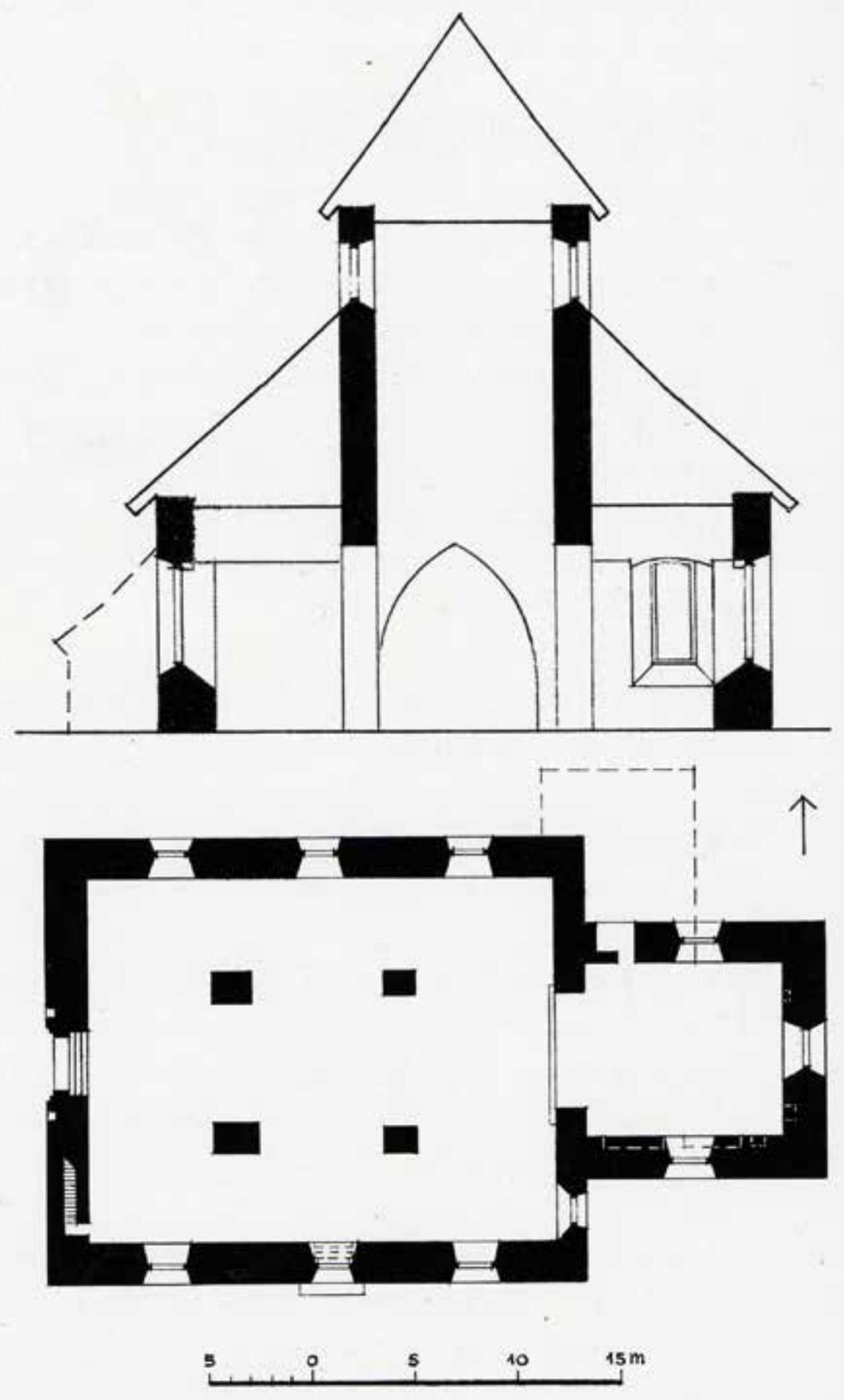

Abb. 26. Grundriss und Querschnitt der Kirche in Rujen. Andris Caune, Ieva Ose, Latvijas viduslaiku mūra baznīcas 12. gs. beigas - 16. gs. sākums, 354 
zu betrachtenden Rippenprofil in der Zukunft auch einen Ausgangspunkt für die Datierung ante quem der Hochwände der Jakobskirche in Riga.

\section{DIE BARTHOLOMÄUSKIRCHE IN RUJEN}

Als ein Vorbild der Kirche zu Urbs ist von den Fachleuten auch die Kirche in Rujen angeboten worden. Die Kirche in Rujen hat wiederholte Zerstörungen und Umbauten durchgemacht. Jedoch ist dort der historische Gesamtumfang mitsamt ihrem dreijochigen basilikalen Langhaus erhalten geblieben, wobei die Arkadenbögen niedrig sind und die Hochwände über eine Vertikalgliederung verfügen.

Die Kirche in Rujen brannte im Jahre 1974. Daraufhin hat der Architekt Uldis Pastnieks aufgrund der Betrachtung der Ruinen eine Konzeption des Werdegangs der Kirche vorgelegt. Die Arbeit ist zwar unveröffentlicht geblieben, aber seine Standpunkte werden in einigen späteren Publikationen zum Ausdruck gebracht. Gemäß der Vermutung des Architekten sind in der Entwicklungsgeschichte der Kirche vier Bauperioden zu unterscheiden. Die Außenwände der Kirche, bei welchen auch Backsteine eingesetzt worden sind, sind in den fünfziger und den sechziger Jahren des 13. Jahrhunderts errichtet worden; die Decke des damaligen Langhauses stützte sich auf Holzpfosten. Darauffolgend sind ungefähr zwischen den fünfziger und den achtziger Jahren des 15. Jahrhunderts zwei stabile Pfeiler im westlichen Teil des Langhauses errichtet worden - eventuell, um einen Glockenturm zu stützen. Die dem basilikalen Raum charakteristischen Hochwände und womöglich auch die Rippengewölbe stammen erst aus der dritten Bauperiode, die auf den Zeitraum zwischen 1643 und 1645 datiert worden ist. ${ }^{54}$

Ohne die Argumente der vorgelegten Konzeption zu kennen, ist es schwer, ihre Stichhaltigkeit zu bewerten. Die Begründung der Datierung der ursprünglichen Kirche findet sich jedoch andernorts: die Kirche sei ungefähr zur gleichen Zeit mit der Ordensburg Rujen gebaut worden, nämlich 1259-1263. ${ }^{55}$ Die Bauzeit, auf die hingewiesen wird, stammt leider aus dem

54 Jānis Kalnačs, The Heritage of Religious Architecture and Art in Valmiera District (Riga: Neptuns, 2010), 87. Jedoch ist ein Plan, der angeblich auf den Hypothesen von Uldis Pastniekis basiert, publiziert worden, laut dem sowohl die Pfeiler des Langhauses als auch die Gewölbe der Seitenschiffe ganz und gar auf einen Zeitraum von der zweiten Hälfte des 15. Jahrhunderts bis zum Anfang des 16. Jahrhunderts datiert werden (Caune, Ose, Latvijas viduslaiku mūra baznīcas, 355).

55 Marina Levina, „Rūjena Lutheran church”, Eiropa - kopīgs mantojums. Baznīcas Latvijā (Rìga: Valsts kultūras pieminekḷu aizsardzības inspekcija, 1999), 93. 
Verzeichnis der Burgen der Chronik von Johann Gottfried Arndt, der aufgrund einer bereits vor einem Jahrhundert abgegebenen Bewertung unter „Mystifikationen“ leide. ${ }^{56}$ Die tatsächliche Errichtung der Burg in Rujen fand offenbar in der ersten Hälfte des 14. Jahrhunderts statt. ${ }^{57}$

Am meisten Zweifel ruft aber die Datierung der Hochwände hervor: eine Basilika mit solch niedrigen Arkaden passt keineswegs in das beginnende Zeitalter des Barocks, als eher eine Einheitlichkeit des Raumes angestrebt wurde. Im Falle des estnischen Materials [zum Beispiel die Johanniskirche in Narwa (estnisch: Narva)] erscheint es als klar, dass wenigsten im nördlichen Teil des Baltikums das gotische Formrepertoire damals noch nirgendwohin verschwunden war. ${ }^{58}$ Jedoch ist zu untersuchende Formlösung in den vierziger Jahren des 17. Jahrhunderts äußerst fragwürdig und die vorgelegte Hypothese würde einer äußerst gründlichen Argumentation bedürfen.

Im vorliegenden Artikel versucht man gar nicht erst, den Werdegang der Kirche in Rujen zu erläutern. Im Moment ist nur die Tatsache von Bedeutung, dass auch dort die Hypothese einer Basilika aus dem 13. Jahrhundert auf jeden Fall beiseite gelassen werden muss. Es sei hinzugefügt, dass die estnischen Autoren sich bei Verweisen auf Rujen einzig und alleine auf den von Reinhold Guleke publizierten Grundriss ${ }^{59}$ gestützt haben, ohne die Kirche selbst zu kennen.

\section{ZWISCHENZUSAMMENFASSUNG}

Es stellt sich also heraus, dass die betrachteten Vergleichsobjekte bei der Aufklärung der Baugeschichte der Kirche zu Urbs tatsächlich wenig Hilfe leisten. Deutlich wird jedoch, dass die basilikalen Langhäuser Alt-Livlands im allgemeinen Fall nicht im Laufe einer Bauperiode ganzheitlich fertig gestellt worden sind und eine standardisierte Rigenser Baurichtung des 13. Jahrhunderts nie existiert hat. Der gemeinsame Nenner aller Kirchen, die wir im vorliegenden Artikel bisher besprochen haben, besteht in den kurzen und stämmigen Pfeilern und den niedrigen Arkaden, weshalb der Raum ziemlich archaisch wirkt. Allem Anschein

56 Karl von Löwis of Menar, Burgenlexikon für Alt-Livland (Riga: Walters und Rapa, 1922), 42.

57 Andris Caune, Ieva Ose, Latvijas 12. gadsimta beigu - 17. gadsimta vācu pil̨u leksikons. Latvijas viduslaiku pilis, IV (Rīga: Latvijas vēstures institūta apgāds, 2004), 23, 426.

58 Krista Kodres, „Rootsiaegne kogudusekirik Eestis”, Kunstiteaduslikke uurimusi, 8 (Tallinn: Teaduste Akadeemia Kirjastus, 1995), 59-62.

59 Guleke, Alt-Livland, F. II T. III. 
nach standen dahinter rein praktische Erwägungen. Bei dem Umbau der Kirche zu einer Basilika diktierten die vorhandenen Außenwände die Höhe der Seitenschiffe, diese wiederum waren für die niedrigen Arkadenbögen verantwortlich. Um einen geräumigeren Raumeindruck erzielen zu können, hätte man auch die Außenwände umgestalten müssen, das hätte aber einen unvergleichlich größeren Bauumfang bedeutet. Neben den gemeinsamen Zügen sollte aber ebenso der Unterschied in der Gestaltung der Hochwände erwähnt werden. In der Jakobskirche in Riga gibt es mehrstufige Wandvorlagen, in der Nikolaikirche in Pernau wiederum einfache Lisenen. In den Kirchen in Rujen und in Urbs dahingegen fehlt den Hochwänden jegliche Vertikalgliederung. Demnach handelt es sich offenbar nicht um das Schaffen des gleichen Meisters oder der gleichen Bauhütte.

Bei allen zu betrachtenden Fällen gibt es keine Anhaltspunkte für die Datierung dieser umfangreichen Umbauten. Nur in Bezug auf die Nikolaikirche in Pernau haben wir auf die Möglichkeit hingewiesen, dass die Neugestaltung der Kirche um die zwanziger Jahre des 15. Jahrhunderts herum stattgefunden haben könnte. Aufmerksamkeit verdient die Tatsache, dass in eben diesem Zeitraum in Reval (estnisch: Tallinn) Entwicklungen stattfinden, die auf den ersten Blick eigenartig erscheinen. Nämlich werden in Reval im Laufe des im 15. Jahrhunderts eingesetzten Baubooms die Olai- und die Nikolaikirche zu Basiliken umgestaltet. Beide erhalten auch ein neues Sanktuarium mit Chorumgang, dies sind aber vor allem Kennzeichen einer bischöflichen Kathedrale. Im Allgemeinen ist das diesbezügliche Kennwort einer spätmittelalterlichen Stadtkirche die Hallenkirche - es handelt sich um eine bewusste Gegenüberstellung der Stadtbürgerschaft und der bischöflichen Strukturen. Von dieser Hauptrichtung unterscheidet sich aber die Entwicklung in den Hansestädten. Dort manifestierte sich die reiche Kaufmannschaft durch die Erkennungszeichen der Gotik der Kathedralen, die vor allem in einer Basilika und in einem Chorumgang bestehen - die Bahnbrecherin ist hier die Marienkirche in Lübeck. ${ }^{60}$ Offensichtlich wird die neue Raumform der Gemeindekirchen der Hansestädte Riga und Pernau auch von der gleichen Ideologie getragen.

60 Hans-Joachim Kunst, „Der Chor der Marienkirche in Lübeck. Eine Neubestimmung der Herkunft seiner Formen", Mittelalterliche Backsteinarchitektur und bildende Kunst im Ostseeraum, Wissenschaftliche Beiträge der Ernst-Moritz-Arndt-Universität Greifswald (Greifswald, 1987), 23-24. 
Der Hinweis auf die Vorlieben der Hansestädte hilft uns aber nicht bei der Aufklärung der Entwicklungsgeschichte der Kirche zu Urbs weiter. Bei Urbs handelte es sich um kein wichtiges Zentrum, noch nicht mal um ein Hakelwerk und es wäre hinfällig, von daher nach irgendeiner Ideologie von Großkaufleuten zu suchen. Warum wurde aber in Urbs eine Basilika errichtet?

\section{DIE BASILIKA IN URBS - DIE IDEOLOGIE DER KIRCHENPATRONE?}

Bei der Errichtung von mittelalterlichen Kirchen haben die Bauherren eine gewichtige Rolle gespielt. Es hat sich meistens allerdings um eine Institution gehandelt haben - zum Beispiel um ein Domkapitel. Im allgemeinen Fall erhält der Bauherr der Kirche auch das Patronatsrecht. Die entsprechenden Angaben über Alt-Livland sind äußerst knapp und bisher hat sich die Forschung mit diesem Thema nicht viel beschäftigt. Die früheren Fachleute haben ziemlich resolut behauptet: „im Mittelalter hatte kein Laienpatronat an livländischen Pfarrkirchen bestanden ". ${ }^{61}$ Die gründlichste Abhandlung des Patronatsrechts im mittelalterlichen Alt-Livland stammt von Erkki Olavi Kuujo, ${ }^{62}$ der auch mehrere gegenteilige Beispiele anführt. Offensichtlich ist die Situation in den Territorien unterschiedlicher Machthaber in Alt-Livland ziemlich verschieden gewesen, schließlich bestand hier ein ähnliches territoriales Flickenmuster wie im Deutschen Reich. So wurden in Wierland (estnisch: Virumaa) Vasallenfamilien zu den Patronen mehrerer Kirchspielkirchen. ${ }^{63}$ In Bezug auf den Bistum Dorpat gibt es kaum entsprechende Angaben. Die deutlichsten Informationen liegt über Kawelecht/Pohja (estnisch: Puhja) vor: im Jahre 1397 vererbte Bartholomäus von Tiesenhausen sei-

61 Leopold Arbusow jr, Die Einführung der Reformation in Liv-, Est- und Kurland (Leipzig: Heinsius, 1921), 816.

62 Erkki Olavi Kuujo, Die rechtliche und wirtschaftliche Stellung der Pfarrkirchen in Alt-Livland. Suomalaisen Tiedeakatemian Toimituksia, B. 79, Nr. 2 (Helsinki, 1953), 52-70.

63 Paul Johansen, Die Estlandliste des Liber Census Daniae (Reval: F. Wassermann; Kopenhagen: H. Hagerup, 1933), 209-210. Es geht um Parochialkirchen. Ein Thema an sich bilden aber die Eigenkirchen, die dem Hochadel gehörten, siehe: Kersti Markus, „Keskaegsed maavaldused - uus allikas arhitektuuriuurijale", Acta Historica Tallinnensia, 10 (Tallinn, 2006), 6-10. 
nen Kindern der lenwar der kerke to Pujen. ${ }^{64}$ Dass der Begriff lenwar das Patronatsrecht bedeutet, wird aus einem Text aus dem Jahre 1464 klar, welcher den Altar des Heiligen Leibes und die Vikarie der Peterskirche in Riga behandelt: leenware, de ym latin iuspatronatus genand is. ${ }^{65}$

In einer Situation, in der die direkten Informationen über das Patronatsrecht knapp sind, verdienen die engen Kontakte des hiesigen Hochadels mit dem Bischof und den Institutionen des Bistums etwas Aufmerksamkeit. Viele Adeligen gehörten dem Dorpater Domkapitel an - darunter fünf Mitglieder der Familie von Tiesenhusen. ${ }^{66}$ Besonders augenfällig waren die Kontakte mehrerer Adelsfamilien zum Zisterzienser-Kloster zu Falkenau (estnisch: Kärkna). ${ }^{67}$ Es wurde auch die Errichtung der Domkirche unterstützt. So sollen Peter und Wolmar Üxküll im Jahre 1477 zum Zwecke des Bauens der Domkirche und für weitere Bedürfnisse dem Domkapitel 200 Rigenser Mark ${ }^{68}$ gegeben haben, ebenso haben sie versprochen, der Kirche zwei Glocken zu stiften. Es handelte sich übrigens nicht um einen einseitigen Wohltätigkeitsakt: als Gegenleistung bestätigte der Dorpater Bischof Johannes II Bertkow den von Üxkülls das Lehnsrecht innerhalb ihrer Besitztümer. ${ }^{69}$ Eine so dichte Symbiose des Hochadels und der Kirche trifft man wahrscheinlich in keiner weiteren Gegend Alt-Livlands an.

Hierbei sollte einem Sachverhalt aus den Anfangsjahren des Bistums Dorpat besondere Aufmerksamkeit geschenkt werden. Im Jahre 1224 belehnte der Bischof Hermann fünf vornehme Männer und ehrwürdige Ritter jeweils mit einem gesamten Kirchspiel. ${ }^{70}$ Axel von Gernet hat

64 Liv-, Est- und Curländisches Urkundenbuch, VI, hrsg. von Friedrich Georg von Bunge (Riga: N. Kymmel, 1873), Nr. 2941. Gleiches wiederholt sich auch im Jahr 1449 im Testament: Est- und livländische Brieflade 1, hrsg. von Friedrich Georg von Bunge und Robert von Toll (Reval: Kluge und Ströhm, 1857), Nr. 197.

65 Kuujo, Die rechtliche und wirtschaftliche Stellung, 64.

66 Tõnis Lukas, Tartu toomhärrad 1224-1558 (Tartu: Tartu Ülikooli Kirjastus, 1998), 89.

67 Wolfgang Schmidt, „Die Zisterzienser im Baltikum und in Finland”. Suomen Kirkkohistoriallisen Seuran vuosikirja 1939-1940 (Helsinki, 1941), 144-149; Kaur Alttoa, „Kärkna tsistertslaste klooster”, Padise ja Vantaa. Keskaja sild Padise ja Vantaa vahel. Keskiajan silta Padisen ja Vantaan välilla (Padise, 2012), 37-39.

68 Anmerkung des Übersetzers: Eine Rigenser Mark war eine Silbermünze mit dem Gewicht von $207,8 \mathrm{~g}$.

69 „...hirumme yn unse domkerke tom buwete unde ander nothorftighet gegeven unseme capitelle twehundert olde mark Riges, van verden varberurt, unde sollen noch yn de sulve unse domkerke unde geven twe merklike clocken, de voarmals tome Odempe yn sunte Ylsbeten capelle ghewest syn." Livländische Güterurkunden (aus den Jahren 1207 bis 1500), Bd. I, hrsg. von Hermann von Bruiningk und Nicolais Busch (Riga: Jonck \& Poliewsky, 1908), Nr. 518.

70 Henriku Liivimaa kroonika, übersetzt von Richard Kleis, editiert und kommentiert von Enn Tarvel (Tallinn: Eesti Raamat, 1982), XXVIII, 7. Siehe auch Tarvel, „Sakala ja Ugandi kihelkonnad”, 591-593. 
vermutet, dass es sich um ein Burglehen gehandelt hatte. ${ }^{71}$ Es liegen keine Informationen vor, ob mit dieser Belehnung auch das jeweilige Patronatsrecht einherging, aber das kann keinesfalls ausgeschlossen werden. Auf jeden Fall muss man aufgrund dieser Informationen, auf die oben hingewiesen wurde, die Möglichkeit mitberücksichtigen, dass ambitiöse Vasallen eine bedeutende Rolle beim Bauen von Kirchspielkirchen spielten.

Über das Patronatsrecht der Kirche zu Urbs sind die Angaben lückenhaft und auf den ersten Blick sogar widersprüchlich. Anhand der Daten der Revision der Jahre 1624 bis 1627 befand sich die Kirche zu Urbs zur Hälfte auf den Ländereien des Gutshofes Anzen (estnisch: Antsla), der den von Üxkülls gehörte, und zur anderen Hälfte auf den Ländereien von Uelzen (den Ueltzischen Landen, estnisch: Vaabina), welche den von Tiesenhausens gehörten. Die Kirche soll von den genannten zwei Familien gebaut worden sein und ihnen beiden gehörte auch das Patronatsrecht. ${ }^{72}$ Die Visitation des Jahres 1613 gibt dahingegen bekannt, dass die Kirche zu Urbs dem Gutshof Uelzen (Fabianmuis) gehört habe. In Zusammenhang mit dem Gut Anzen hat man damals zwar zahlreiche Kapellen (sacellum) der Umgebung erwähnt, während gleichzeitig betont wird, dass es in diesem Gebiet keine Kirche gab. ${ }^{73}$

In Wirklichkeit bestand in diesen angeführten Informationen kein Widerspruch. Das Gut Anzen hatte im Mittelalter den von Üxkülls gehört, die während des Livländischen Krieges ihren Besitz verloren. ${ }^{74}$ Im Jahre 1591 wurde aber das Krongut (folvark) von Anzen gegründet, ${ }^{75}$ das von einem königlichen Ökonomen geleitet wurde. Es besteht kein Grund zu der Annahme, dass damit irgendwelche kirchlichen Verpflichtungen oder auch Privilegien einhergingen. Die Revision des Jahres 1613 fixierte nur den momentanen Zustand. Glaubwürdig ist aber, dass die Revision der Jahre von 1624 bis 1627 die Rechtsbeziehungen während der Bischofszeit genau wiedergibt. Demnach kann man mit hoher Wahrscheinlichkeit

71 Axel von Gernet, Verfassungsgeschichte des Bisthums Dorpat bis zur Ausbildung der Landstände, Verhandlungen der Gelehrten Estnischen Gesellschaft zu Dorpat, XVII (Jurjew (Dorpat), 1896), 142. 72 Das Dorpater Land 1624/27, Hefte zur Landeskunde Estlands, 1, hrsg. von Oleg Roslavlev (München, 1965), 9.

73 „Protocoll der Catholischen Kirchenvisitation in Livland vom Jahre 1613”, 32.

74 Leonhard von Stryk, Beiträge zur Geschichte der Rittergüter Livlands, I (Dorpat: C. Mattiesen, 1877), 190.

75 Enn Tarvel, Fol'vark, pan i poddannyj: agrarnye otnošenija v pol'skich vladenijach na territorii Južnoj Éstonii v knce XVI - načale XVII veka (Tallinn: Akademija nauk Ėstonskoj SSR, 1964), 60. 
den Schluss ziehen, dass das Patronatsrecht der Kirche zu Urbs den zwei einflussreichsten Familien des Bistums Dorpat gehörte.

Im Mittelalter manifestiert die Macht sich oftmals auch durch die Architektur. Im Bistum Dorpat ist ein Beispiel hierfür die Kirche in Kawelecht, die unter dem Patronat der von Tiesenhausens stand, und wo die Außenwände des Langhauses in der Länge des gesamten Perimeters durch Nischen für Seitenaltäre gegliedert sind. ${ }^{76}$ Unter den hiesigen Landkirchen stellt das eine große Ausnahme dar. Offensichtlich ist hier die Domkirche zu Dorpat das Vorbild gewesen und der Patron wollte seine Heimkirche durch die "Zitierung" ihres Vorbildes veredeln. Ich würde es wagen zu behaupten, dass hinter der basilikalen Raumlösung der Kirche zu Urbs vor allem die Ambitionen der Bauherren stehen, ihre Bedeutung mit Hilfe von kirchenbaulichen Zeichen zu visualisieren. In dieser Beziehung war eine Basilika eine sehr sichere Wahl.

\section{URBS UND DIE WALLFAHRT}

Unter den knappen historischen Angaben ist zweifelsohne jene Auskunft die irritierendste, dass die Kirche zu Urbs zu einem offiziellen Wallfahrtsort erklärt wurde. Gleich entsteht die Frage, ob man daraus irgendetwas auch über die Errichtung der Kirche herauslesen könnte. Zumindest Armin Tuulse hat in Bezug auf die Vasallenburg Ringen (estnisch: Rõngu) und der dortigen Kapelle des Heiligen Kreuzes behauptet, dass aufgrund der Zeit der Ablasserteilung ungefähr auch die Zeit der Fertigstellung des entsprechenden Gebäudes abgeleitet werden kann. ${ }^{77}$ Eine solche Schlussfolgerung ist jedoch überstürzt, zumindest liegen keine Angaben vor, die eine solche Behauptung bestätigen würden. Aus dem Bistum Dorpat gibt es entsprechende nähere Angaben nur über die Antoniuskapelle in Dorpat. Den Besuchern dieser Kapelle gewährte der Papst im Jahre 1432 den Ablass, die Errichtung der Kapelle wird aber auf den Zeitraum von etwa zwanzig Jahren zuvor datiert. ${ }^{78}$

Die große Anzahl der Wallfahrtsorte im spätmittelalterlichen Bistum Dorpat ist augenfällig. Aus dem 14. Jahrhundert sind entsprechende Informationen nur in Bezug auf die Burgkapelle in Neuhausen (estnisch:

76 Kaur Alttoa, „Märkmeid Lõuna-Eesti keskaegsetest maakirikutest”, Ars Estoniae medii aevi. Grates Villem Raam, Viro Doctissimo et Expertissimo (Tallinn: Eesti Muinsuskaitse Selts, 1995), 77.

77 Tuulse, Die Burgen in Estland und Lettland, 264.

78 Kaur Alttoa, „Kahest Antoniuse kabelist ja ühest sealoost”, Kleio, 2 (Tartu, 1989), 22. 
Vastseliina) vorhanden. ${ }^{79}$ Im Jahre 1413 gewährte der Papst Johannes XXIII. den Ablass zusätzlich noch für die Besucher der Parochialkirche in Ringen und auch denjenigen der Kapelle des Heiligen Kreuzes der Burg Ringen. Ein größeres Ablasspaket kam im Jahre 1432 hinzu: der Papst Eugen IV. versprach den Ablass sowohl den Besuchern der Marienkapelle der Kirche (der Domkirche?) in Dorpat ${ }^{80}$, denjenigen der Antoniuskapelle ebenfalls in Dorpat als auch den der Kirche der Gemeinde Tooma in Kirrumpäh (estnisch: Kirumpää). ${ }^{81}$ Irgendwann ist zu dieser Reihe auch Warbeck (estnisch: Kastre) hinzugekommen, welches in einem Testament aus dem Jahre 1450 als Wallfahrtsort erscheint. ${ }^{82}$ Versteckt sich hinter dieser großen Anzahl ein explosionsartiger Zuwachs an Wallfahrten oder handelte es sich um eine Abwertung des Themas der Wallfahrt - die Unterlagen, die Estland und auch die Nachbarländer behandeln, bieten uns keine befriedigende Antwort. ${ }^{83}$ Es ist jedoch klar, dass zumindest zum jetzigen Zeitpunkt anhand der Informationen aus dem Jahre 1413 keine baugeschichtlichen Schlussfolgerungen über die Kirche zu Urbs gezogen werden können. Eindeutig ist nur, dass die Kirche in irgendeiner Form damals bereits existiert haben muss.

\section{ZUM SCHLUSS}

Im Rahmen des jetzigen Forschungsstandes ist es nicht möglich, irgendetwas Endgültiges über die bauliche Entwicklung der Kirche zu Urbs zu sagen. Jedenfalls sind im Langhaus Elemente vorhanden, die nicht älter sein können, als aus dem 14. Jahrhundert. Zugleich muss die Möglichkeit in Betracht gezogen werden, dass es sich nicht um ein homogenes Gebäude handelt, sondern dass es dort mehrere bauliche Aufschichtungen gibt.

Das Verbinden der Kirche zu Urbs mit anderen Basiliken Alt-Livlands (der Jakobskirche in Riga, der Nikolaikirche in Pernau sowie der Bartholomäuskirche in Rujen) ist wenigstens aufgrund der heutigen

79 Paul Johansen, „Das Wunder von Neuhausen in Estland”, Zeitschrift für Ostforschung, H. 3 (Marburg, 1954), 1-7.

80 capella beatae Marie virginis in ecclesia Tarbatensis.

81 Arbusow, Livlands Geistlichkeit vom Ende des 12. bis ins 16. Jahrhundert, 312-313, 315-316.

82 Merit Jakobson, „Eestpalverännak”: palverännakukorraldused keskaegsetes Lübecki testamentides, Magisterarbeit, Universität Tartu (2010), 11. Die Information stammt aus: Martin Wehrmann, „Der Memorienkalender (Necrologum) der Marien-Kirche in Lübeck”, Zeitschrift des Vereins für Lübeckische Geschichte und Altertumskunde, 6/1 (1890/1892), 61.

83 Gespräch des Autors mit Christian Krötzl in Turku (Finnland) am 26. August 2013. 
Informationen wenig begründet. Offenbar muss die gesamte Hypothese über die Existenz einer Rigenser Bauschule im 13. Jahrhundert beiseite gelassen werden. Ihre basilikale Form erhielt die Kirche zu Urbs nicht vor dem letzten Viertel des 14. Jahrhunderts - womöglich erst im 15. Jahrhundert. Die unter den Landkirchen außergewöhnliche Raumform zeugt aber offensichtlich von den Ambitionen der Kirchenpatrone, die dem Hochadel angehörten und die ihre Ansprüche auch durch die Architektur zum Ausdruck bringen wollten.

Kaur Alttoa: Urvaste Church and the Question of the Riga School of Construction in the 13th Century

Keywords: Urvaste Church, medieval ecclesiastical arChitecture in Estonia, thirteenth century Riga School of Construction, patronage Rights, pilgrimage CHURChes

SUMMARY:

Although Urvaste Church is the only basilica parish church in Estonia it has received little to no attention in the literature of architecture. In most cases it has been considered an instance of the reputedly coherent thirteenth century school of construction of Riga that among others includes St Jacob's Church in Riga, St Nicholas Church in Pärnu, and Church of Saint Bartholomew in Rujiena. Based on this assumption, it is often claimed that Urvaste Church was built in entirety during the thirteenth century.

In Urvaste Church, an exceptional construction method is seen: below the roof of the aisles there are abutments that support the walls of the nave. In the diocese of Tartu, the same construction type is found in two more cases: it is used in the Tartu Dome Church, and in St John's Church, Tartu. Based on these buildings, it is reasonable to believe that the central nave of Urvaste basilica Church is not built before the last third of the fourteenth century. In addition, St Jacob's Church in Riga, St Nicholas Church in Pärnu, and Church of Saint Bartholomew in Rujiena attained basilica form in the course of later reconstruction work and therefore the hypothesis about a homogeneous thirteenth century school 
of construction in Riga is incorrect. It is argued that it may be the case that the basilica plan of Urvaste Church expresses the aspirations for a certain kind of representation by the church patrons of the high nobility.

CV:

Kaur Alttoa is a long-time scholar and teacher of art history at the University of Tartu as well as one of the foremost specialists of the history of medieval architecture in the Baltic region. His objects of interest have included both medieval fortresses and sacral buildings. Among his major contributions stands out the restoration and study of the St. John's Church in Tartu, which was also published as a monograph in 2011. 